\title{
Diversity of diatoms, benthic macroinvertebrates, and fish varies in response to different environmental correlates in Arctic rivers across North America
}

Jennifer Lento ${ }^{1}$, Sarah M. Laske², Isabelle Lavoie ${ }^{3}$, Daniel Bogan ${ }^{4}$, Bob Brua ${ }^{5}$, Stéphane Campeau $^{6}$, Krista Chin ${ }^{7}$, Joseph M. Culp ${ }^{8}$, Brianna Levenstein ${ }^{1}$, Michael Power ${ }^{9}$, Émilie Saulnier-Talbot ${ }^{10}$, Rebecca Shaftel ${ }^{4}$, Heidi Swanson ${ }^{9}$, Matthew Whitman ${ }^{11}$, Christian E. Zimmerman ${ }^{2}$

${ }^{1}$ Canadian Rivers Institute and Department of Biology, University of New Brunswick, Fredericton, New Brunswick, Canada

${ }^{2}$ U.S. Geological Survey, Alaska Science Center, Anchorage, Alaska, USA

${ }^{3}$ Institut national de la recherche scientifique, Centre Eau Terre Environnement, Quebec, Canada

${ }^{4}$ Alaska Center for Conservation Science, University of Alaska Anchorage, USA

${ }^{5}$ Environment and Climate Change Canada, Watershed Hydrology and Ecology Research Division, Saskatoon, SK, Canada

${ }^{6}$ Department of Environmental Sciences, Université du Québec à Trois-Rivières, Trois-Rivières, Québec, Canada

${ }^{7}$ Cumulative Impacts Monitoring Program, Government of the Northwest Territories, Yellowknife, Northwest Territories, Canada

${ }^{8}$ Environment and Climate Change Canada and Wilfrid Laurier University, Department of Biology and Department of Geography and Environmental Studies, Waterloo, Ontario, Canada

${ }^{9}$ Department of Biology, University of Waterloo, Waterloo, Ontario, Canada

${ }^{10}$ Laboratoire de paléoécologie aquatique, Centre d'études nordiques (CEN), Université Laval, Canada

${ }^{11}$ US Bureau of Land Management, Arctic District Office, Fairbanks, Alaska, USA

Running Head: North American Arctic river biodiversity

\section{Keywords}

freshwater, river ecology, latitudinal gradient, climate change, biodiversity monitoring 


\section{Abstract}

1. Climate change poses a significant threat to Arctic freshwater biodiversity, but impacts depend upon the strength of organism response to climate-related drivers. Currently, there is insufficient knowledge about Arctic freshwater biodiversity patterns to guide assessment, prediction, and management of biodiversity change.

2. As part of the Circumpolar Biodiversity Monitoring Program's first freshwater assessment, we evaluated diversity of diatoms, benthic macroinvertebrates, and fish in North American Arctic rivers. Alpha diversity was assessed in relation to temperature, water chemistry, bedrock geology, and glaciation history to identify important environmental correlates. Biotic composition was compared among groups to evaluate response to environmental gradients.

3. Macroinvertebrate alpha diversity declined strongly with increasing latitude from $48^{\circ} \mathrm{N}$ to $82^{\circ} \mathrm{N}$, whereas diatom and fish diversity peaked around $70^{\circ} \mathrm{N}$ without a clear latitudinal decline. Macroinvertebrate diversity was significantly positively related to air temperature. Diatom diversity was related to bedrock geology and temperature, whereas fish diversity was related to glaciation history.

4. Fish and macroinvertebrate assemblages differed between sites in western Canada, where invertebrate composition was more variable, and Alaska, where fish composition was more variable. In sites with both diatom and macroinvertebrate data, diatom composition was distinct in Alaska, where richness was highest in former glacial refugia. Macroinvertebrate composition was distinct in lowest-latitude eastern and high-latitude western Canadian sites where temperature was warmest.

5. Temperature, precipitation, geology, calcium, and substrate size were important environmental correlates for diatoms and macroinvertebrates, though the relative importance of each correlate differed. Diatom taxa were most strongly associated with water 
chemistry, whereas benthic invertebrate composition related most strongly to precipitation and temperature.

6. This large-scale study provides the most substantial integration and analysis of river diatom, macroinvertebrate, and fish data from the North American Arctic to date. Findings suggest that macroinvertebrates will show the strongest response to climate-related shifts in temperature, whereas diatoms and fish are more likely to respond to climate-induced shifts in nutrients and hydraulic connectivity. However, significant gaps in data coverage limited our ability to reliably evaluate spatial patterns and detect change. These gaps could be reduced by improving collaborative efforts between the U.S.A. and Canada to harmonize future monitoring. 


\section{Introduction}

Freshwater biodiversity is an important resource in Arctic North America, providing economic, cultural, and aesthetic value (Dudgeon et al., 2006). But biodiversity is changing at an unprecedented rate, with Arctic ecosystems experiencing the greatest threat from the changing climate (Heino et al., 2020; Sala et al., 2000). Biodiversity in Arctic rivers, measured as species richness and assemblage composition, has been found to vary as a function of the physical and chemical characteristics of the habitat (Wrona et al., 2013). Low levels of light and nutrients, cold temperatures, a short growing season, and the presence and persistence of snow and ice cover limit productivity in Arctic rivers (Prowse et al., 2011; Wrona et al., 2013); as a consequence, fewer species tend to inhabit high-latitude systems. For example, there is strong evidence of latitudinal declines in riverine benthic macroinvertebrate diversity related to lower temperatures and unfavorable climate factors at higher, Arctic latitudes (Castella et al., 2001; Culp, Lento, Curry, Luiker, \& Halliwell, 2019; Lento et al., In Review; R. W. Scott, Barton, Evans, \& Keating, 2011). Freshwater fish diversity also declines northward across the entirety of the North American continent, with northern latitudes supporting a subset of highly migratory, cold tolerant species (Griffiths, 2010). Available evidence suggests that freshwater diversity is lower in the Arctic than at temperate latitudes (Vincent \& Laybourn-Parry, 2008; Wrona et al., 2013), though few studies have assessed diversity patterns at a broad, continental scale.

Taxonomic groups (e.g., fish versus benthic macroinvertebrates) may respond differently to similar environmental gradients, which can confound generalized latitude-richness gradients that support a decline in species richness with latitude (Castella et al., 2001; Hillebrand, 2004; Wrona et al., 2013). Across the longitudinal expanse of Arctic North America, patterns of biodiversity (taxonomic richness and composition) may also vary with large-scale differences in glaciation history, geology, climate, and hydrology (Antoniades, Douglas, \& Smol, 2009; Griffiths, 2010; R. W. Scott et al., 2011). For example, taxonomic richness and composition of diatom assemblages are strongly related to underlying geology, flow rates, sediment types, and 
water chemistry (Antoniades \& Douglas, 2002; Antoniades et al., 2009; Kristiansen, 1996; Wrona et al., 2013), while macroinvertebrate richness and composition may be controlled by additional factors, including primary productivity or disturbance regimes (Jacobsen \& Dangles, 2012; R. W. Scott et al., 2011; Vinson \& Hawkins, 2003). Among Arctic fish assemblages, species richness is related to historical glaciation events and the connectivity of freshwater habitats, where time since the last glaciation, freshwater access, and species migratory ability may limit colonization (Dias et al., 2014; Griffiths, 2010; Laske et al., 2019; Oswood, Reynolds, Irons III, \& Milner, 2000).

The response of various taxonomic groups to climate change may depend in part on the relative importance of climate-influenced drivers (e.g., temperature) versus climate-independent drivers (e.g., geology; Culp, Lento, et al., 2012; Schindler \& Smol, 2006; Wrona et al., 2013). Changes in climate-influenced physical and chemical drivers, like temperature, hydrology, and nutrient loading have the potential to alter the distribution and abundance of lotic species, change stream community structure (Prowse et al., 2011; Wrona et al., 2006), and affect species richness of algae, macroinvertebrates, and fish (Heino, Virkkala, \& Toivonen, 2009; Wrona et al., 2013). For example, paleolimnological analysis has indicated increasing diversity of diatoms in high Arctic lakes with increasing temperature over time (Michelutti, Douglas, \& Smol, 2003). Increasing temperatures may also enhance productivity of primary producers, which can lead to greater algal biomass accumulation or increased herbivory (Wrona et al., 2006). Further, warming is likely to contribute to changes in macroinvertebrate diversity or abundance (Slavik et al., 2004). Fishes will respond with increased metabolism that will drive increases in prey consumption rates and influence growth and reproduction (Reist et al., 2006). Furthermore, the northward range expansions of cool- and warm-water species, and range contractions of cold-water species, are likely to change the composition and diversity of Arctic stream communities (Chu, Mandrak, \& Minns, 2005; Heino et al., 2020; Wrona et al., 2013). 
Widespread assessment of biotic responses to a changing climate has been lacking for North America's Arctic rivers (Culp, Goedkoop, et al., 2012; Rouse et al., 1997). Yet, it is highly important to gather data that provide a sufficient baseline to 1) define a monitoring network that can detect biodiversity change, and 2) evaluate spatial and temporal changes in aquatic resources (Culp, Lento, et al., 2012; Heino et al., 2020; Heino et al., 2009). To support circumpolar monitoring and assessment, the Arctic Freshwater Biodiversity Monitoring Plan from the Freshwater Group of the Circumpolar Biodiversity Monitoring Program (CBMP) identified Focal Ecosystem Components (FECs), or indicator taxa groups that are ecologically pivotal, charismatic, or sensitive to change (Culp, Goedkoop, et al., 2012; Culp, Lento, et al., 2012). This paper assesses the patterns and trends of three FECs -- diatoms, benthic macroinvertebrates (hereafter, "macroinvertebrates"), and fish -- across North American Arctic rivers and streams and evaluates their association with different abiotic variables. Our analyses are based on the largest data compilation to date for these three FECs in North American Arctic rivers, and contribute to the goals of identifying monitoring gaps and key monitoring locations, as well as evaluating spatial diversity patterns. Specifically, our aim was to address the following questions: 1) how does diversity vary spatially and what are the primary environmental correlates of diversity for FECs across Arctic North America, and 2) do environmental gradients drive similar community responses among FECs? We predicted that FECs would vary in their response to environmental correlates, with diatom diversity relating to bedrock geology/water chemistry, macroinvertebrate diversity relating to temperature, and fish diversity showing the strongest relationship to environmental variables associated with glaciation history and spatial dispersal. First, we compared latitudinal patterns of alpha diversity for each FEC and evaluated patterns related to environmental correlates. Second, we assessed spatial patterns in river community biodiversity where data for multiple FECs existed, by analyzing FEC pairs (diatom\&macroinvertebrate and macroinvertebrate\&fish). Finally, we used our findings to 
identify spatial gaps in monitoring coverage and examine which FECs best reveal environmental change and are most useful for future freshwater biodiversity monitoring in the Arctic.

\section{Methods}

This paper analyzes data from the freshwater database of the CBMP (CBMP-Freshwater database; available on the Arctic Biodiversity Data Service, abds.is) as part of the first circumpolar freshwater assessment of the Conservation of Arctic Flora and Fauna (CAFF) working group of the Arctic Council (Lento et al., 2019). North American data were identified for the CBMP-Freshwater database from existing monitoring databases (federal, provincial and state monitoring data, and academic data stored in national or regional databases) where applicable, as well as from searches of published peer-reviewed literature, grey literature including government data reports, and industry monitoring reports. Data collection was not exhaustive due to funding limitations and time constraints, but effort was made to maximize spatial coverage of data for each FEC. The analysis here focused on rivers (excluding lakes/ponds) because we achieved a relatively robust spatial distribution of riverine data in both Canada and Alaska.

\section{Biological Data Selection and Harmonization}

Because data came from a number of different sources (see data sources at abds.is) and sample collection methods varied among sites, we used a subset of the data to ensure comparability. Diatom samples were generally collected and processed by scraping the biofilm from hard substrates, or less often, soft surface sediments, digesting samples, and sorting until a minimum of $\sim 400$ valves were identified (see Kahlert et al., 2020 for more details). The majority of macroinvertebrate samples from Canada were collected and processed following Canadian Aquatic Biomonitoring Network (CABIN) protocols (Environment Canada, 2012, 2014), which include time-limited (3-min) sampling with a 400- $\mu \mathrm{m}$-mesh kicknet, subsampling using a Marchant box, and identification of a minimum of 300 individuals. Similar sampling protocols were used for the majority of macroinvertebrate samples from Alaska, which were 
collected using a 500- $\mu$ m-mesh kicknet. A small number of additional samples $(<1 \%$ of macroinvertebrate samples) collected using Surber samplers with 400- to 500- $\mu$ m-mesh were included from Canada and Alaska to increase spatial coverage (as area-restricted net and kicknet samples produce similar assemblage composition estimates; Brua, Culp, \& Benoy, 2011). Samples collected by ponar or Ekman grabs were excluded because methods were not comparable. Fish sampling methods varied and included hook and line, backpack electrofishing, fyke nets, minnow traps, seines, weirs, or a combination of methods. Ninety-six percent of the fish sites were sampled with multiple gear types or a single gear that can sample whole assemblages (e.g., fyke net). Of the remaining four percent of sites, angling was the predominant method of capture, and at those sites, it is possible that small bodied fishes, if present, may have been excluded from sampling. Assessment of fish data was included as presence/absence, given the expectation that sampling bias (dictated by the gear type) would influence abundance. Further, any data collected from commercial fishing or harvest were removed because they generally did not include counts for the full fish assemblage. The final dataset included 1482 sites (defined as river locations with unique geospatial coordinates) with data for one or more FECs (diatom, macroinvertebrate and/or fish assemblages) from rivers in North America (Fig. 1).

The large number of data sources required that we harmonize nomenclature to ensure comparability. For diatoms, macroinvertebrates, and fish, nomenclature was adjusted to update any outdated naming conventions and adjust for any regional differences in naming. Some diatoms taxa were grouped into species complexes to control for ambiguous taxonomic identifications and to group easily mis-identified taxa (see Kahlert et al., 2020 for further details about diatom nomenclature adjustment). Analyses were conducted at the adjusted species level (with species complexes) for diatoms, and at the species level for fish. Macroinvertebrate data were analyzed at a higher taxonomic level because samples from a number of regions were only identified to family or order level, and because difficulty in identification of small-bodied 
individuals to genus or species resulted in a high degree of mixed-level taxonomy for the remaining samples. Family-level analysis of macroinvertebrate data allowed for the inclusion of the majority of samples and reduced the need to eliminate taxa due to mixed-level taxonomy. Analysis at the family level for insects (family or higher for non-insects) has been shown to retain ecological response patterns (sensu Bowman \& Bailey, 1997), although such data must be interpreted conservatively as higher taxonomic levels are not exact surrogates of species level-responses (Heino, 2014). However, a preliminary assessment of our data using a selection of samples with genus-level data indicated that although diversity estimates were higher with genus data than with family data, diversity patterns among regions were similar. Samples with order-level identification for macroinvertebrates (generally only in Alaska) were removed from the diversity assessment, but were retained for multiple-FEC analysis of macroinvertebrate and fish sites to increase the sample size for Alaska (see details on that analysis below).

Single-FEC Diversity Assessment

Biological Data Processing

Diversity assessment focused on spatial comparisons of alpha diversity, or local taxonomic richness, and therefore data were converted to presence/absence for all FECs, rather than relative abundance (Fig. S1). All FECs were sampled once between June and September (early October for a small number of southern macroinvertebrate sites) and few sites were sampled in more than one year. Diatom data were collected between 2007 and 2015, with single sampling events for all sites. Macroinvertebrate data were collected between 1998 and 2015 , and approximately $12 \%$ of sites had data for $2-5$ years. Fish sites were primarily sampled between 2001 and 2010, though two sites were sampled from 1993-1998, and less than 4\% of sites had data for multiple years (2-6 years). Where multiple samples were collected at a single site, samples were combined (i.e., maximum value for presence/absence across all samples) for a more accurate assessment of the number of taxa at the site. Alpha diversity was estimated at a regional level using rarefaction (rather than at the site level; see below for details), and 
combining samples avoided potential bias that could be introduced by selecting only one of the available samples from each site.

Site Classification and Geospatial Processing

To ensure site classification for analysis reflected natural flow boundaries and differences in large-scale environmental factors that change regionally (e.g., temperature), sites were grouped by catchment and ecoregion for assessment of diversity (rarefied estimates of local richness) and extraction of broad-scale geospatial variables (Fig. 1A). Sites were first grouped into hydrobasins, which are catchments standardly derived at different spatial scales (Lehner \& Grill, 2013), ranging from level 01, at the continent scale, to level 12 at the smallest sub-basin scale. Level 05 Hydrobasins (mid-scale sub-basins) were chosen for the alpha diversity assessment (Fig. 1A). At a larger spatial scale, sites were classified by ecoregion according to the Terrestrial Ecoregions of the World (TEOW; Olson et al., 2001; Fig. 1A). TEOW defines ecoregions based on distinct assemblages and environmental conditions, including climate. The Arctic TEOW are smaller than the larger, flow-based Freshwater Ecoregions of the World (FEOW; Abell et al., 2008). In some instances, sites within the same hydrobasin were grouped separately to reflect the fact that the hydrobasin crossed two ecoregions (Fig. 1A).

At the same hydrobasin/ecoregion scale, geospatial variables describing long-term air temperature, glaciation history, and bedrock geology (Fig. 2A-C) were included in this analysis to test the primary predictions of the study (see detailed description and sources in Table 1A). Variables extracted for each hydrobasin/ecoregion intersection included the average long-term annual (LTA; 1970-2000) maximum August air temperature, as a proxy for water temperature and the magnitude of summer extremes; the proportion of the hydrobasin with ice cover during the last glaciation, as a measure of glacial refugia and connectivity; and the relative area of each hydrobasin/ecoregion intersection that was underlain by sedimentary bedrock (present across much of the North American Arctic), as a large-scale descriptor of the chemical habitat (because geology strongly influences overlying water chemistry; Reimann et al., 2009). 
Analysis of Alpha Diversity and Environmental Correlates

The number of taxa encountered increases as the number of samples collected in an area increases (until an asymptote is reached; Colwell et al., 2012; Colwell, Mao, \& Chang, 2004), and rarefaction was used to account for regional differences in sampling effort, with alpha diversity estimated at the hydrobasin/ecoregion scale. Rarefaction curves were created in EstimateS Version 9 (Colwell, 2013) through a randomization procedure with 100 iterations, ensuring curves were extrapolated as needed to at least 10 nodes (equivalent to 10 sites; see Colwell et al., 2004 for details on extrapolation of rarefaction curves). For each FEC, the mean alpha diversity, standard deviation, and 95\% confidence interval was estimated at the rarefied level of 10 sites for each hydrobasin/ecoregion intersection (Fig. S1; see details in Colwell \& Elsensohn, 2014; Colwell et al., 2004). Mean rarefied alpha diversity \pm standard deviation was plotted as a function of the average latitude of sites in each hydrobasin/ecoregion intersection to explore latitudinal trends for diatoms, macroinvertebrates, and fish. Only hydrobasin/ecoregion intersections with more than three sites were included in this analysis to avoid extrapolation of richness from only 1-3 sites.

The relationship of alpha diversity with environmental correlates was assessed at the hydrobasin/ecoregion scale using least-squares linear regression analysis (Fig. S1). For each FEC, we tested the full model: diversity = temperature + sedimentary + glaciation, where diversity was the rarefied alpha diversity at 10 sites, temperature was the mean LTA maximum August air temperature, sedimentary was the relative area of sedimentary bedrock, and glaciation was the relative area of ice cover during the last glaciation (Table 1A). The full model was compared with all possible reduced models, including individual variables or combinations of two variables, as well as a null model, and the most parsimonious model with the lowest AICc (corrected Akaike Information Criterion) was selected as the best model to describe richness patterns for that FEC. For macroinvertebrate sites, which covered a latitudinal gradient in both eastern and western Arctic North America (defined as hydrobasins east or west of $100^{\circ} \mathrm{W}$ ) 
where temperatures are known to differ (Prowse et al., 2006b), comparisons were made between regression slopes by adding a categorical term for hydrobasin location (east or west) to the model and using Analysis of Covariance to test the interaction between the location term and temperature (Fig. S1). Alpha diversity was $\log _{10}$-transformed for each FEC to improve homogeneity of variance of the residuals. The relative area of sedimentary bedrock and glaciation area were logit-transformed as needed to further stabilize residual variance. Regression analyses were completed in Systat 12 (Version 12.02). Added variable plots for multiple regressions were created in R version 3.6.0 (R Development Core Team, 2015) using the CAR package (Fox \& Weisberg, 2019).

\section{Multiple-FEC Patterns}

\section{Data Selection and Processing}

To examine how patterns in composition compared among FECs, analyses were conducted on subsets of sites that had data for multiple FECs (Fig. S1). There were only two river sites in the database with data for diatoms, macroinvertebrates, and fish, thus precluding assessment of all three FECs. Instead, separate analyses were conducted on sites with data for both diatoms and macroinvertebrates $(n=130)$ and those with data for both macroinvertebrates and fish ( $n=19$; Fig. 1C, Fig. S1). Sites with macroinvertebrates and fish data were located in western Canada (in the Northern Canadian Shield Taiga, Muskwa-Slave Lake Forests, and Northwest Territories Taiga) and Alaska (Arctic Coastal Tundra) (Fig. 1C); samples were not generally collected on the same date because different FECs were collected by different operators, but were collected in the same season (e.g., summer), and were generally collected within the same year or one year apart over the period 2003-2013 (single sampling events). Sites with diatom and macroinvertebrate data were located across Canada and Alaska and extended into the high Arctic (Fig. 1C); samples were collected on the same day by the same operators over the period 2007-2015 (single sampling events). Analysis of diatom\&macroinvertebrate stations used relative abundance data at the adjusted species level 
(diatoms) and family level (macroinvertebrates; Fig. S1). Fish presence/absence data were analyzed at species level for the assessment of macroinvertebrate\&fish stations. Benthic macroinvertebrate data for this assessment were analyzed at order level (with the exception of Chironomidae at the family level) to include samples from Alaska, and were analyzed as relative abundance to maximize the detection of compositional differences at the coarse taxonomic resolution (Fig. S1).

Abiotic data collected in the field (water chemistry and habitat descriptors) were available for the majority of diatom\&macroinvertebrate sites, though inconsistencies in measured parameters across sites (due to the large number of data sources) limited the number of comparable parameters. Available and comparable data included major ions, total phosphorus (TP), and the predominant geologic substrate size (classified into categories following the Wentworth scale; Wentworth, 1922; see Table 1B for details). Geospatial data extracted for each hydrobasin/ecoregion intersection were also considered for analysis of bioticabiotic relationships for diatom\&macroinvertebrate sites, including LTA air temperature, precipitation, and bedrock geology (see Table 1C for details and sources).

Water chemistry and other habitat descriptor data were not available for most of the macroinvertebrate\&fish sites, and the few macroinvertebrate\&fish stations covered a small geographic range (i.e., few hydrobasin/ecoregion intersections); therefore, geospatial data were not variable enough to differentiate among sites, and analysis of biotic-abiotic relationships could not be completed for this FEC pair.

Analysis of Assemblage Patterns

Multiple-FEC patterns in assemblage composition were assessed using multivariate analysis (Fig. S1). Principal Components Analysis (PCA) was run separately for each FEC in each of the data comparisons (diatom\&macroinvertebrate and macroinvertebrate\&fish) to visualize and assess the variation among sites with respect to assemblage structure. PCA was chosen for ordination of macroinvertebrate\&fish assemblages because spatial turnover of fish 
and macroinvertebrate assemblages was low due to the low numbers of sites and taxa in the analysis (first axis gradient length < 2.5 SDs; Detrended Correspondence Analysis; ter Braak \& Šmilauer, 2002), and a linear model therefore provided the best fit to the data. PCA with postanalysis standardization of species scores (to represent correlations on the ordination diagram; ter Braak \& Šmilauer, 2002) was conducted separately on fish data and macroinvertebrate data (Fig. S1). Procrustes analysis (Jackson, 1995) was then used to compare ordinations for each FEC comparison and assess whether the spatial arrangement of stations in multivariate space was more similar between FECs than could occur by chance (Fig. S1). In this analysis, the macroinvertebrate ordination (rotational matrix) was rotated and translated as needed to match the fish ordination (target matrix), and the Procrustean sum of squared residuals $\left(m_{12}^{2}\right)$ provided a measure of the deviation in sample points between ordinations (Jackson, 1995). The fit of the two ordinations was analyzed with a randomization test to determine whether it was closer than could occur by chance (Jackson, 1995).

There were many more sites and taxa in the diatom\&macroinvertebrate assessment, and a Hellinger transformation was applied to the data because of the large number of zeroes in the site-by-taxa data matrices (Legendre \& Gallagher, 2001). Linear methods were used for ordination of the diatom and macroinvertebrate data because spatial turnover was moderate in these assemblages (first axis gradient length of 2.8 SDs; Detrended Correspondence Analysis; ter Braak \& Šmilauer, 2002). PCA was chosen because it identifies the gradients along which there is the greatest variation among sites and is considered appropriate for analyzing community data when a Hellinger transformation has been applied (Legendre \& Gallagher, 2001). PCA with post-analysis standardization of species scores was used to separately analyze Hellinger-transformed diatom data and macroinvertebrate data (Fig. S1). Because of the large number of taxa (particularly for diatoms), some data adjustment was necessary prior to analysis to allow a focus on major trends. Hence, taxa that made up less than $2 \%$ of the relative abundance across all 130 sites were removed from analysis (reducing from 275 to 161 diatom 
taxa and from 46 to 32 taxa for macroinvertebrate). PCA ordinations were compared using Procrustes analysis, with the diatom ordination as the target matrix and the macroinvertebrate ordination as the rotational matrix, as described above.

Analysis of Environmental Correlates

Redundancy Analysis (RDA) was further used with the diatom\&macroinvertebrate data to identify key environmental correlates of assemblage structure for each FEC and the significance of correlates was assessed and compared among FECs. Prior to analysis, a subset of environmental variables was selected by evaluating a correlation matrix of all candidate water chemistry, habitat, and geospatial parameters (see Table 1B-C) and choosing variables that summarized (i.e., were highly correlated with) several other parameters or were uncorrelated with other parameters, and that were judged ecologically meaningful (i.e., were expected to affect diatom or macroinvertebrate assemblage structure). The resulting subset of variables (see Table 1B-C) was $\log _{10}$ - or logit-transformed, as appropriate. Separate RDAs were run for diatoms and macroinvertebrates using these environmental variables (Fig. S1), and the variance explained by each axis was compared with the total variance in the biotic assemblage (unconstrained variance, from the PCAs) to assess the strength of the association of chosen environmental variables with patterns among sites. The significance of each RDA axis and of each environmental variable was assessed using a Monte Carlo permutation test, with conditional effects of environmental variables tested after the order of inclusion in the model was selected based on marginal effects. All ordinations were run in Canoco Version 4.55 (ter Braak \& Šmilauer, 2002). Procrustes analysis was run in R version 3.6.0 (R Development Core Team, 2015) using the vegan package (Oksanen et al., 2015).

\section{Results}

Single-FEC Diversity Assessment 
Alpha diversity within hydrobasins showed strong latitudinal trends for macroinvertebrates, but weak latitudinal patterns for diatoms and fish (Fig. 3). Macroinvertebrate alpha diversity showed a strong decline with increasing latitude, decreasing from $>50$ taxa at $50^{\circ} \mathrm{N}$ to $<10$ taxa at $82^{\circ} \mathrm{N}$ (Fig. 3B). In western North America, macroinvertebrate alpha diversity was variable among hydrobasins, but was generally higher than diversity in eastern hydrobasins at similar latitudes (Fig. 3B). Both diatoms and fish had elevated alpha diversity at around $70^{\circ} \mathrm{N}$, which represented only hydrobasins in the Arctic Coastal Tundra ecoregion in Alaska (Fig. 3A, 3C). Diatom alpha diversity was otherwise steady across nearly $20^{\circ}$ of latitude (Fig. 3A), whereas alpha diversity of fish increased across the narrow $10^{\circ}$ of latitude, but was not estimated north of $72^{\circ} \mathrm{N}$.

The strength of the relationship between alpha diversity and environmental correlates varied among the FECs (Table 2). The regression model with the lowest AICc for diatoms was one that included both sedimentary bedrock and LTA maximum August air temperature (adjusted $\left.R^{2}=0.33, \mathrm{RMS}=0.021\right)$. Alpha diversity of diatoms (log-transformed) increased significantly with increasing relative area of sedimentary bedrock (logit-transformed; $p=0.005$; Fig. 4A) and increasing maximum air temperature ( $p=0.037$; Fig. 4B), though standardized regression coefficients indicated a stronger relationship with bedrock geology $\left(b^{\star}=0.798\right)$ than with temperature $\left(b^{\star}=0.554\right)$. Fish alpha diversity was most related to the relative area of the hydrobasin with ice cover during the last glaciation (model with the lowest AICC), with diversity (log-transformed) decreasing with increasing glaciated area (slope $=-0.188$ ). It was a weak relationship, however, that was not significant $\left(p=0.145, r^{2}=0.15, \mathrm{RMS}=0.026\right.$; Fig. $\left.4 \mathrm{C}\right)$ and the fit of the model did not differ from the fit of a null model $(\triangle \mathrm{AICC}=0.559)$.

The strongest regression models for macroinvertebrate alpha diversity were those that included temperature, and the most parsimonious model that described macroinvertebrate alpha diversity as a function of only temperature had the lowest AICc. Macroinvertebrate alpha diversity (log-transformed) was strongly positively related to air temperature $\left(r^{2}=0.82\right.$; RMS $=$ 
0.011). Because there are known temperature differences between the eastern and western North American Arctic that were predicted to affect diversity, macroinvertebrate alpha diversity data were further separated by location. Though alpha diversity increased as a function of temperature in both regions, the slopes of the relationship differed in eastern and western North America (Analysis of Covariance, temperature*location interaction $F_{1,40}=12.04, p<0.001$ ). The relationship for eastern hydrobasins was less variable and had a steeper slope (east slope $=$ $0.068, r^{2}=0.97, \mathrm{RMS}=0.005 ;$ west slope $\left.=0.040, r^{2}=0.56, \mathrm{RMS}=0.010\right)$ and a lower intercept (indicating lower diversity; east intercept =0.493; west intercept =0.846; Fig. 4D, 4E). Regression results indicated an increase of 8.1 taxa with an increase of $5^{\circ} \mathrm{C}$ in the east, and an increase of 6.5 taxa with an increase of $5^{\circ} \mathrm{C}$ in the west.

\section{Multiple-FEC Patterns}

\section{Macroinvertebrates and Fish}

Analysis of fish and macroinvertebrate assemblages at sites where both were sampled indicated a dissimilarity between sites in western Canada (Northern Canadian Shield Taiga, Muskwa-Slave Lakes Forests, and Northwest Territories Taiga) and Alaska (Arctic Coastal Tundra) that was evident for both FECs (Fig.5), resulting in macroinvertebrate and fish ordinations that were more similar than could occur by chance (Procrustes $m_{12}^{2}=0.67, p=$ 0.003). For fish, the separation between sites in western Canada and Alaska dominated the first PCA axis, which explained $39 \%$ of the variation in the data. This separation was driven by more than eight species of fish that were positively correlated with Alaskan sites (including Alaska blackfish Dallia pectoralis, ninespine stickleback Pungitius pungitius, broad whitefish Coregonus nasus, humpback whitefish Coregonus pidschian, and least cisco Coregonus sardinella; Fig. 5A). Alaska sites were further spread along the second axis gradient (which explained $17.6 \%$ of the variation) based on their varying associations with these taxa (Fig. 5A). In contrast, sites from western Canada were tightly clustered and positively associated with few species (primarily lake chub Couesius plumbeus and pike Esox lucius). Ordination of macroinvertebrate 
data indicated a similar separation between sites from western Canada and Alaska along the second axis, which explained $27.3 \%$ of the variation (Fig. $5 \mathrm{~B}$ ). The first axis of the macroinvertebrate ordination described a gradient among western Canada sites that explained $37.7 \%$ of the variance; on this axis Ephemeroptera and Plecoptera loaded positively and Chironomidae loaded negatively. Sites from Alaska, which were associated with non-chironomid Diptera and Mollusca, were more tightly clustered along the first axis than sites from Canada (Fig. 5B). Overall, strong differences between western Canada and Alaska for both FECs contributed to the similarity between ordinations.

Diatoms and Macroinvertebrates

Diatoms and macroinvertebrates showed strong differences in assemblage composition among some groups of sites in the PCA ordinations, notably indicating distinct diatom composition in Alaskan sites (AK $70^{\circ} \mathrm{N}$ West, Arctic Coastal Tundra and Arctic Foothills Tundra) and distinct macroinvertebrate composition in low-latitude eastern Canadian sites (58 $\mathrm{N}$ East, Torngat Mountain Tundra and Eastern Canadian Shield Taiga) and high-latitude western Canadian sites ( $72^{\circ} \mathrm{N}$ West, Middle Arctic Tundra and Arctic Coastal Tundra) (Fig. 6). Although there were differences between the ordinations with respect to the groups of sites that dominated each axis, scaling and rotation of the ordinations through Procrustes analysis indicated that the ordinations were still more similar than could be obtained by chance (Procrustes $\left.m_{12}^{2}=0.84, p=0.001\right)$.

The diatom ordination indicated a gradient among sites along the first axis (explaining $17.8 \%$ of the variation) that separated sites from the far north and northwest, on Banks Island (Arctic Coastal Tundra and Middle Arctic Tundra; $72^{\circ} \mathrm{N}$ West) and Ellesmere Island (High Arctic Tundra; $81^{\circ} \mathrm{N}$ East), from sites at lower latitudes in the east (Middle Arctic Tundra at $63^{\circ} \mathrm{N}$ East; Torngat Mountain Tundra and Eastern Canadian Shield Taiga at $58^{\circ} \mathrm{N}$ East). Sites at the north of Baffin Island (High Arctic Tundra; $72^{\circ} \mathrm{N}$ East) were distributed across the entire gradient (Fig. 6A). Along the first axis, sites from $72^{\circ} \mathrm{N}$ West and $81^{\circ} \mathrm{N}$ East were associated with a number of 
species and species complexes in the genera Diatoma, Ulnaria, Meridion, Synedra/Hannea, and Fragilaria, as well as the species Achnanthidium minutissimum, whereas sites from $63^{\circ} \mathrm{N}$ East were more strongly associated with species in the genera Eunotia, Frustilia, Brachysira, and Pinnularia (Fig. 6A). The distinction of Alaskan sites from other diatom sites was evident along the second axis (explaining $14.0 \%$ of the variation), and was due to a strong association of a large number of taxa with Alaskan sites, including species of the genera Navicula, Sellaphora, Nitzschia, and Eolimna (Fig. 6A).

Analysis of biotic-abiotic relationships indicated that calcium (Monte Carlo permutational $F$-ratio $=15.89 ; 499$ permutations) and the presence of sand/silt (Monte Carlo permutational $F$ ratio $=15.83 ; 499$ permutations) were the most important environmental correlates for diatoms (Table 3). Calcium dominated the first axis of the diatom RDA, which explained $12.5 \%$ of unconstrained variance in the diatom assemblages, and the percent sedimentary bedrock was positively correlated with calcium along this axis. High calcium sites in the north and west $\left(72^{\circ} \mathrm{N}\right.$ West and $81^{\circ} \mathrm{N}$ East) separated from those that were negatively correlated with calcium in the east $\left(58^{\circ} \mathrm{N}\right.$ East and $63^{\circ} \mathrm{N}$ East; Fig $\left.7 \mathrm{~A}\right)$. LTA maximum August air temperature was negatively related to the highest latitude sites of the High Arctic Tundra on Ellesmere Island $\left(81^{\circ} \mathrm{N}\right.$ East) along this axis, though it had a weaker conditional effect than calcium (Fig 7A, Table 3). On the second axis, which explained $11.7 \%$ of the variation, sites in Alaska separated from all remaining sites due to positive correlation with sand/silt (Fig. 7A). The Alaskan and western Banks Island sites $\left(72^{\circ} \mathrm{N}\right.$ West) were also positively associated with the relative area of sedimentary bedrock, precipitation CV, sodium concentration, and TP (Fig. 7A).

Ordination of sites based on macroinvertebrate assemblages indicated a strong separation of the most diverse sites from those with fewer taxa (Fig. 6B). In contrast to diatoms, the Alaskan sites in the macroinvertebrate PCA were tightly grouped with most Canadian sites on the first two axes near the origin of the ordination (Fig. 6B), and separation of Alaskan sites from other sites was only evident on the third axis (Fig. S2). The first axis, explaining 36.3\% of 
the variation in assemblage composition, separated lower-latitude eastern sites (58 $\mathrm{N}$ East), western sites on Banks Island $\left(72^{\circ} \mathrm{N}\right.$ West $)$, and a few sites in the High Arctic Tundra $\left(72^{\circ} \mathrm{N}\right.$ East) from the remaining sites. Along the first axis, positive values (primarily near sites from $58^{\circ} \mathrm{N}$ East) were associated with a diverse range of taxa, including many families of Ephemeroptera, Plecoptera, and Trichoptera, whereas the tight cluster of remaining sites (including sites from $63^{\circ} \mathrm{N}$ East, $72^{\circ} \mathrm{N}$ East, $81^{\circ} \mathrm{N}$ East, and $\mathrm{AK} 70^{\circ} \mathrm{N}$ West) was predominantly associated with the cold-tolerant taxa Chironomidae and Oligochaeta (Fig. 6B). The second axis, which explained $15.8 \%$ of the variance, showed the separation of the sites at $58^{\circ} \mathrm{N}$ East from those on Banks Island $\left(72^{\circ} \mathrm{N}\right.$ West) and a small number of sites on northern Baffin Island (72 ${ }^{\circ} \mathrm{N}$ East) (Fig. 6B). Low-latitude sites from $58^{\circ} \mathrm{N}$ were associated with several mobile taxa of Ephemeroptera (Heptageniidae, Ephemerellidae), Plecoptera (Capniidae, Chloroperlidae, Perlodidae), and Trichoptera (Hydropsychidae, Rhyacophilidae, and Glossosomatidae). Sites from Banks Island $\left(72^{\circ} \mathrm{N}\right.$ West) and northern Baffin Island $\left(72^{\circ} \mathrm{N}\right.$ East) were associated with Baetidae (Ephemeroptera), Nemouridae (Plecoptera ), and the extreme-cold-tolerant family Tipulidae (Diptera).

Analysis of biotic-abiotic relationships for macroinvertebrates indicated precipitation $\mathrm{CV}$ (Monte Carlo permutational $F$-ratio $=29.27 ; 499$ permutations) and sedimentary bedrock (Monte Carlo permutational $F$-ratio $=11.44 ; 499$ permutations) were the most important environmental correlates (Table 3), though temperature was also important on the first axis (Fig. 7B). The first axis explained $22.9 \%$ of the unconstrained variance in the macroinvertebrate assemblages, driven by lower-latitude eastern sites ( $58^{\circ} \mathrm{N}$ East) where LTA maximum August air temperature was high and precipitation CV was low (Fig. 7B). Sites on Banks Island ( $72^{\circ} \mathrm{N}$ West) also differed from all other sites due to high temperatures, but they were positively correlated with high variability in precipitation, similar to most other sample locations (Fig. 7B). The weaker, but significant, effect of temperature in the RDA model (Monte Carlo F-ratio $=3.03 ; 499$ permutations; Table 3) was likely due to multi-collinearity between precipitation and 
temperature; temperature was added to the model after precipitation because it had lower marginal effects, but excluding precipitation $\mathrm{CV}$ from the model resulted in temperature having the strongest conditional effects (results not shown). Along the second axis, which accounted for $7.3 \%$ of the variance, sites separated along a gradient of sedimentary bedrock area, sodium, calcium, predominance of sand/silt, and TP, all of which were positively associated with sites from Alaska and Banks Island $\left(70^{\circ} \mathrm{N}\right.$ West and $72^{\circ} \mathrm{N}$ West, respectively; Fig. 7B).

\section{Discussion}

This is the first continent-wide biodiversity analysis of riverine diatoms, benthic macroinvertebrates, and fish in Arctic North America. As such, these are the first analyses able to evaluate the distribution of available data and identify data gaps, information that will assist in the design of future monitoring efforts and improve the ability to detect changes in aquatic biodiversity. Furthermore, our results provide critical information about links between freshwater biodiversity and environmental correlates in North American Arctic rivers, which aid in the detection of biotic responses to continued climate change. We found that biodiversity response to environmental correlates differed among the FECs, even though FECs indicated similar spatial composition patterns. Macroinvertebrate diversity was strongly related to gradients in latitude and temperature, while, surprisingly, that of diatoms and fish was not. Temperature played a secondary role in structuring diatom assemblages, but diatom diversity showed stronger relationships with underlying geology and water chemistry. Fish diversity was associated with glaciation history, with more species and distinct assemblage composition in high latitude regions free of ice during the last glaciation (180k BP). These results allow for improved predictions about climate change impacts on Arctic river assemblages, as they suggest that macroinvertebrates will show the strongest direct response to shifts in temperature, whereas diatom and fish assemblages may respond indirectly to climate-induced shifts in water chemistry and changes to flow and connectivity, respectively. 


\section{Temperature as a primary correlate of river macroinvertebrate diversity}

The strongest relationship between FEC richness and temperature occurred for the macroinvertebrates. Alpha diversity increased with increasing temperature, and the relationship was particularly strong in eastern North America. This was likely due to long-term stability in air temperatures in the eastern Canadian Arctic (Prowse et al., 2006b) that has left the latitudinal temperature gradient in this region relatively unchanged, thus supporting greater distinction in temperature and diversity among latitudes. The relationship between macroinvertebrate richness and latitude was less pronounced in the more climatically variable ecoregions of northwestern Canada and Alaska, where the effects of climate change have been more prevalent (Culp et al., 2019; Prowse et al., 2006b) and diversity was highly variable among hydrobasins. In our study, the coldest sites (e.g., those at $81^{\circ} \mathrm{N}$ East and $63^{\circ} \mathrm{N}$ East) were most strongly associated with Chironomidae and Oligochaeta, consistent with glacial studies that indicate only oligochaete worms and the dipteran families of Chironomidae (subfamilies Diamesinae and Orthocladiinae in particular), Tipulidae, and Simuliidae can tolerate the coldest stream habitats with maximum temperatures of $2-4^{\circ} \mathrm{C}$ (Milner, Brittain, Castella, \& Petts, 2001; Milner \& Petts, 1994). Cold temperatures have been shown to limit macroinvertebrate diversity where physiological thresholds are exceeded (Blaen, Brown, Hannah, \& Milner, 2014; Castella et al., 2001; Friberg, Milner, Svendsen, Lindegaard, \& Larsen, 2001; Irons III, Miller, \& Oswood, 1993; Milner \& Petts, 1994). Extreme climate conditions at high latitudes, including a short growing season, reduced summer temperatures, and freezing substrate limit distributions of macroinvertebrate taxa (Chertoprud, Palatov, \& Dimante-Deimantovica, 2017; Culp et al., 2019; Danks, 2007; R. W. Scott et al., 2011). In addition, the decline in temperature and growing season length with increasing latitude places constraints on the availability of resources for macroinvertebrates (Vinson \& Hawkins, 2003), ultimately limiting high latitude alpha diversity. 
Although temperature was clearly a predominant correlate, macroinvertebrate diversity was also related to variation in precipitation, bedrock geology, substrate type, and water chemistry. Poff (1997) proposed that hierarchical drivers are environmental filters, acting successively to select taxa that can tolerate the conditions in a particular location. It follows, therefore, that climate variables may be the primary environmental filters that determine which macroinvertebrate taxa can survive at high latitudes in the North American Arctic (Danks, 2007). For example, sites in lower latitude ecoregions in the east (Torngat Mountain Tundra and Eastern Canadian Shield Taiga) experienced warmer temperatures and more stable precipitation regimes than other locations, and had higher diversity than sites in climatically extreme higher latitudes $\left(>70^{\circ} \mathrm{N}\right)$. Other environmental correlates, such as bedrock geology and the smaller-scale but related correlates substrate composition and water chemistry, likely act at successively smaller scales (sensu Poff, 1997) to drive compositional differences related to physical habitat preferences across longitudinal gradients and among streams (Culp et al., 2019; Heino et al., 2009; Lento et al., 2013). We found that sedimentary bedrock, sand/silt substrate types, and water chemistry (e.g., calcium, nutrients) were important to macroinvertebrate community assembly, contributing to separation among the less diverse, colder ecoregions due to taxon habitat preferences. These environmental correlates were associated with some case-making caddisfly families and several families of gastropods and molluscs that require calcium for shell formation (Havas \& Rosseland, 1995; Neff \& Jackson, 2013).

Geology and water chemistry as primary correlates of river diatom diversity

Conductivity and $\mathrm{pH}$ are known correlates of diatom assemblage composition in freshwaters (Grenier, Campeau, Lavoie, Park, \& Lek, 2006; Kahlert et al., 2020; Potapova \& Charles, 2003), and such aspects of the chemical habitat are strongly influenced by underlying bedrock geology (Nelson, Rhoades, \& Dwire, 2011; Reimann et al., 2009; Valett, Morrice, Dahm, \& Campana, 1996). In our study, diatom alpha diversity was positively associated with 
the predominance of mineral-rich sedimentary bedrock at high latitudes in the Arctic archipelago and on the Alaskan coast. Sites with low diatom diversity were underlain by Precambrian bedrock, and consequently, had lower pH and ion levels (Hamilton, Gajewski, Atkinson, \& Lean, 2001). Ecological preferences of diatom genera reflected these underlying abiotic gradients; for example, species of the genera Navicula and Nitzschia were associated with Alaskan sites that were dominated by sedimentary bedrock. These genera are mainly circumneutral to alkaliphilous, tolerate elevated concentration of organically-bound nitrogen and are mesoeutraphentic (Van Dam, Mertens, \& Sinkeldam, 1994). In contrast, species of the genera Eunotia, Pinnularia, Frustulia and Brachysira (Anomoeoneis) were positively associated with sites in eastern Canada $\left(58^{\circ} \mathrm{N}, 63^{\circ} \mathrm{N}\right.$, and $72^{\circ} \mathrm{N}$ East) that were underlain by Precambrian bedrock. These species are mainly acidophilus, tolerate very low concentrations of organicallybound nitrogen, and are found in oligotrophic environments (Van Dam et al., 1994).

Diatom diversity also increased with increasing temperature, and unique diatom assemblage composition was found at high latitude sites that were associated with lower temperatures. Similarly, Kahlert et al. (2020) identified characteristic assemblages of river diatoms (biotypes) across the Arctic, and found assemblages that were primarily associated with high Arctic rivers. Some have suggested that diatom diversity is limited at high latitudes due to the low temperatures and short growing season (Wrona et al., 2013), and Michelutti et al. (2003) noted changes in diatom composition and diversity in a high Arctic lake in recent years, coinciding with increasing temperatures. Kahlert et al. (2020) identified temperature as an important correlate of diatom diversity in their circumpolar assessment of lakes and rivers, but concluded that their unimodal relationship between diversity and latitude reflected differences in other environmental variables. In our study, latitudinal patterns in diatom alpha diversity and assemblage composition were associated with a number of other potential correlates, particularly geology and water chemistry, further indicating that temperature may not play a dominant role in driving diatom diversity and assemblage structure in Arctic streams and rivers. 
Historical and contemporary connectivity as a primary correlate of fish diversity

We found that glaciation history was a predominant environmental correlate of fish species richness and assemblage composition (Griffiths, 2015), agreeing with other studies that show environmental history and isolation often play an important role in the distribution and diversity of fishes (Dias et al., 2014; Heino, 2011; Schleuter et al., 2012). Few freshwater fish species occur north of the straits between mainland Canada and the archipelago (Christiansen et al., 2013), and those that do are often tolerant of higher salinity, which allows them to move between fresh and marine waters when necessary. Only two fish species, Arctic charr and ninespine stickleback, occur in the High Arctic Tundra ecoregion on the Canadian Archipelago (W. Scott \& Crossman, 1973), and both are generalist species that are adapted to inhabiting the far north (G. Power, 2002; M. Power, Reist, \& Dempson, 2008). On the mainland, fish diversity was higher in ecoregions with higher colonization potential, including regions with historical refugia or few dispersal barriers (Griffiths, 2010; Oswood et al., 2000). For example, alpha diversity of fish was greatest at latitudes $>70^{\circ} \mathrm{N}$ in rivers of the Arctic Coastal Tundra and Arctic Foothills Tundra, areas that remained ice free during the last glaciation event (Wisconsinan, 180k BP). Notably, fish assemblage composition differed more among sites sampled over a small geographic area in coastal Alaska than among those sampled over a greater geographic area in the Mackenzie River basin, which was affected during the last glaciation. It follows that freshwater fish refugia of unglaciated regions led to the higher present-day diversity (Oswood et al., 2000).

Fish diversity was not directly related to temperature, even though temperature is known to limit species ranges (Jackson, Peres-Neto, \& Olden, 2001). In part, our results may have reflected the lack of fish assemblage data for the Canadian Arctic, as the temperature range tested for fish was much smaller than that for diatoms or macroinvertebrates. For example, only Arctic charr, Salvelinus alpinus, are found above $75^{\circ} \mathrm{N}$ in the Canadian Archipelago 
(Christiansen et al., 2013), where the lowest temperatures were recorded in our study. Fish species composition differed between the Alaskan and Canadian sites, with cold-water species more associated with Alaska sites (e.g., ciscos, burbot), and eurythermic species (e.g., pike) associated with sites in western Canada (Reist et al., 2006). Lack of data in the eastern Canadian Arctic and at the highest latitudes prevented a robust comparison of alpha diversity and compositional change across areas with and without a variable climatic history (i.e., Alaska compared with northeast Canada, where long-term temperatures have been more stable), yet compiled richness data indicates reduced richness in northern and eastern Arctic Canada (Griffiths, 2010; Laske et al., 2019). Even so, we found that colder ecoregions, such as the highelevation Brooks-British Range, had lower fish diversity than adjacent low-elevation ecoregions. Elevation-related thermal conditions, however, cannot be parsed from the effect of the mountains as a dispersal barrier (Oswood et al., 2000), highlighting the importance of additional physical factors in landscape diversity patterns (Heino, 2011).

Potential impacts of climate change on Arctic river biodiversity

The Arctic is warming at nearly twice the rate of the remainder of the globe, potentially leading to regime shifts that threaten biodiversity and ecosystem function (Heino et al., 2020; IPCC, 2014; Sala et al., 2000; Serreze \& Barry, 2011; Wrona et al., 2006). Furthermore, the western Canadian and Alaskan Arctic are projected to continue to experience temperature increases that are relatively greater than temperature changes projected for Northeastern Canada (Wrona et al., 2006). Our results suggest that Alaska is a diversity hotspot for fish and diatoms with distinct assemblages of all three FECs, probably due to connectivity, glacial refugia, and physical and chemical characteristics of the sampled habitats, whereas diversity and compositional patterns of diatoms and macroinvertebrates varied latitudinally and longitudinally across the Canadian Arctic in relation to temperature and geology. Despite similarity in diversity and compositional patterns among FECs, diatoms, macroinvertebrates, 
and fish were related to different environmental correlates, which suggests that the biotic response to changes to the abiotic template will vary among organism groups.

Changes to algal assemblages in response to temperature and precipitation shifts will be mitigated by local water chemistry conditions and their strong influence on algal composition, particularly on diatoms. Shifts in growing season length due to climate change are expected to alter algal assemblages and overall primary production (Prowse et al., 2006a; Vincent et al., 2011; Wrona et al., 2006), although flashier flow regimes may disrupt biofilms (Kendrick, Hershey, \& Huryn, 2019). Long-term trends in water quality in Arctic freshwaters indicate increasing TP in the high Arctic, likely due to release of solutes from thawing permafrost (Huser et al., In Review), which could favour meso-eutraphentic taxa. Increased availability of nutrients with permafrost thaw may further enhance primary productivity, but this may be mitigated by increased sediments causing burial of biofilms (Levenstein, Culp, \& Lento, 2018). Furthermore, increased water temperatures and nutrients may promote growth of cyanobacteria, causing a shift in the composition of algal assemblages (Lürling, Mello, van Oosterhout, de Senerpont Domis, \& Marinho, 2018; Paerl \& Paul, 2012) and impacting food quality for higher trophic levels (Guo, Bunn, Brett, \& Kainz, 2017; Schmidt \& Jónasdóttir, 1997).

Our finding that diversity and composition of macroinvertebrates were strongly associated with climate variables suggests that this FEC might best indicate future climate change impacts. At high latitudes, increasing temperatures are predicted to promote the northward movement of species, leading to increased diversity of macroinvertebrate assemblages in the Arctic (Culp, Lento, et al., 2012; Domisch et al., 2013; Vincent et al., 2011; Wrona et al., 2006). High-Arctic streams are currently dominated by cold-tolerant taxa (e.g., Oligochaeta and Chironomidae; Blaen et al., 2014; Chertoprud et al., 2017; Culp et al., 2019; Lento et al., In Review), but as temperatures increase, thermal tolerance levels for many taxa will no longer prevent immigration of sub-Arctic taxa (e.g., species of Ephemeroptera, Plecoptera, and Trichoptera; Brittain, 2008; Shah, Domisch, Pauls, Haase, \& Jähnig, 2014). 
These northward movements could increase the similarity in assemblage composition between Arctic and Boreal macroinvertebrate communities, leading to declines in regional beta diversity and increases in homogenization of taxa (Culp et al., 2019; Socolar, Gilroy, Kunin, \& Edwards, 2016). The northward movement of sub-Arctic taxa will be further facilitated by shifts in riparian vegetation, landscape shrubification, and the advance of the treeline, which will provide additional allochthonous food resources to stream communities (Wrona et al., 2016). Such changes may result in Arctic stream habitats that support a more diverse range of functional feeding groups of macroinvertebrates (e.g., including shredders and collectors; Wrona et al., 2016; Wrona et al., 2013). However, increased frequency and magnitude of permafrost thaw and ground slumping has the potential to negatively impact macroinvertebrate abundance by increasing suspended solids in adjacent rivers (Chin, Lento, Culp, Lacelle, \& Kokelj, 2016).

Changes to thermal and hydrologic regimes are likely to affect the distribution, survival, and success of Arctic fish species (Dunmall, Mochnacz, Zimmerman, Lean, \& Reist, 2016; Laske et al., 2016; Reist et al., 2006). Given the importance of contemporary and historical surface water connectivity to fish diversity in Arctic North America (Christiansen et al., 2013; Griffiths, 2010; Oswood et al., 2000), changes in the physical environment that either limit or expand colonization potential will be highly important (Rolls et al., 2018; Vincent et al., 2011). Increasing connectivity within stream networks, and between streams and their floodplains, increases alpha diversity; yet, assemblage dissimilarity (i.e., beta diversity) among reaches or catchments may decline, leading to reductions in diversity across larger spatial scales (Dias et al., 2014; Rolls et al., 2018). Furthermore, increasing temperatures at northern latitudes may increase the availability of habitat to eurythermal fishes like pike (Reist et al., 2006). Warming in Alaska's Arctic could improve habitat conditions for pike, increasing their prevalence and enhancing their role as a top predator in Arctic food webs (Byström et al., 2007). Conversely, stenothermic coldwater fishes like Arctic charr S. alpinus could suffer from loss of habitat or contractions of their ranges (Chu et al., 2005; Reist et al., 2006), increased competition from 
other salmonids such as trout (Lento et al., 2019), and/or reduced growth and survival (Sinnatamby, Shears, Dempson, \& Power, 2013) due to rising temperatures.

\section{Future monitoring to detect climate impacts}

Our large-scale study of multiple FECs across the North American Arctic indicated that the response to environmental correlates differed across freshwater organism groups, which suggests that sampling of multiple FECs could provide robust data with the best potential to detect future change in the Arctic. However, few sites had data for multiple FECs, and fewer still had data for all three FECs (diatoms, macroinvertebrates, fish), in part due to a general lack of coordinated monitoring of freshwater biodiversity in the North American Arctic. Our study also identified significant spatial gaps in data coverage for individual FECs across North America that limited our ability to reliably evaluate the response of FECs to different environmental correlates. Although some gaps may have reflected the availability of suitable habitat, for example, in the central Canadian Arctic where lakes and wetlands predominate (e.g., see Kahlert et al., 2020 for assessment of diatom diversity including lakes of central Canada), there was a clear lack of available, comparable data (particularly for diatoms and fish) in other Arctic regions (e.g., eastern Canadian fish data, western Canadian diatom data).

The coordination and harmonization of future monitoring efforts across the North American Arctic, increasing both spatial coverage and the number of FECs sampled at each site, would substantively improve the effectiveness of both regional and circum-Arctic monitoring programs. Broad-scale assessments of change rely on harmonized approaches to monitoring for maximum data comparability, and require coordination of both biotic and abiotic monitoring, in order to support assessment of driver-response relationships. Harmonization of sample processing methods, including taxonomic level for identification of macroinvertebrates, will facilitate accurate estimation of regional diversity. Some measure of harmonization through the use of common, standardized methods of sampling and sample processing would facilitate 
future large-scale assessments of diversity and its response to change. However, monitoring efforts must also be repeatable over time, allowing for temporal analyses. Currently, insufficient long-term datasets exist for the North American Arctic, and few sites have been sampled more than one time, making it impossible to detect temporal change in and among FECs. Repeat sampling to build time series at established sites would support future analysis of biodiversity change in these systems.

The findings of this study aid the U.S.A. and Canada in achieving the CAFF CBMP goal of compiling, harmonizing, and comparing results from existing freshwater studies and monitoring programs (Lento et al., 2019). This was the largest integration and analysis of river diatom, macroinvertebrate, and fish data from the North American Arctic to date, but the uneven spatial coverage of data highlights the importance of increasing collaborative efforts between the U.S.A. and Canada towards future monitoring. Increasing the availability of data through monitoring will aid in the siting and permitting of development, conservation of water and aquatic habitats, and understanding climate impacts on aquatic communities. Further, improved understanding of aquatic communities and biodiversity will facilitate the management and conservation of subsistence resources and the habitats that support northern communities.

\section{Acknowledgements}

The authors wish to thank the staff of the Conservation of Arctic Flora and Fauna office and the co-leads of the Circumpolar Biodiversity Monitoring Program for their support in this process. Thank you to Willem Goedkoop for constructive comments provided on a draft of this manuscript. Thank you to Tim Pascoe of Environment and Climate Change Canada, who helped obtain data permissions and data from the CABIN database. We are grateful to the following, who allowed the use of their CABIN monitoring data: Canadian Zinc, Hatfield Consulting, Newfoundland and Labrador Water Resources Management Division, Ontario Ministry of the Environment (MOE) Cooperative Freshwater Ecology Unit, Parks Canada Nahanni National Park Reserve, Parks Canada Western Arctic Field Unit. We thank everyone 
who participated in field work to collect the circumpolar field data used in this study. Thank you to Beverley Elliott, Julia Howland, and Raja Wetuschat, who helped with data identification, acquisition, and formatting. Any use of trade, firm, or product names is for descriptive purposes only and does not imply endorsement by the U.S. Government.

\section{Data Availability Statement}

Any openly available data used in this study will be available in the Arctic Biodiversity Data Service at abds.is following publication. Restrictions apply to a selection of data that were used under license for this study. Metadata for restricted data will be provided in the Arctic Biodiversity Data Service to indicate data contacts.

\section{Conflict Of Interest Statement}

The authors assert that there are no conflicts of interest.

\section{References}

Abell, R., Thieme, M. L., Revenga, C., Bryer, M., Kottelat, M., Bogutskaya, N., . . Bussing, W. (2008). Freshwater ecoregions of the world: a new map of biogeographic units for freshwater biodiversity conservation. AIBS Bulletin, 58(5), 403-414.

Antoniades, D., \& Douglas, M. S. (2002). Characterization of high arctic stream diatom assemblages from Cornwallis Island, Nunavut, Canada. Canadian Journal of Botany, 80(1), 50-58.

Antoniades, D., Douglas, M. S., \& Smol, J. P. (2009). Biogeographic distributions and environmental controls of stream diatoms in the Canadian Arctic Archipelago. Botany, $87(5), 443-454$

Blaen, P. J., Brown, L. E., Hannah, D. M., \& Milner, A. M. (2014). Environmental drivers of macroinvertebrate communities in high A rctic rivers (S valbard). Freshwater Biology, 59(2), 378-391. 
Bowman, M. F., \& Bailey, R. C. (1997). Does taxonomic resolution affect the multivariate description of the structure of freshwater benthic macroinvertebrate communities? Canadian Journal of Fisheries and Aquatic Sciences, 54, 1802-1807.

Brittain, J. E. (2008). Mayflies, biodiversity and climate change. In F. R. Hauer, J. A. Stanford, \& R. L. Newell (Eds.), International Advances in the Ecology, Zoogeography, and Systematics of Mayflies and Stoneflies (Vol. 128 Entomology pp. 1-14). Berkeley, CA: University of California Press.

Brua, R. B., Culp, J. M., \& Benoy, G. A. (2011). Comparison of benthic macroinvertebrate communities by two methods: Kick-and U-net sampling. Hydrobiologia, 658(1), 293-302.

Byström, P., Karlsson, J., Nilsson, P., Van Kooten, T., Ask, J., \& Olofsson, F. (2007). Substitution of top predators: effects of pike invasion in a subarctic lake. Freshwater Biology, 52(7), 1271-1280.

Castella, E., Adalsteinsson, H., Brittain, J. E., Gislason, G. M., Lehmann, A., Lencioni, V., . . . Snook, D. L. (2001). Macrobenthic invertebrate richness and composition along a latitudinal gradient of European glacier-fed streams. Freshwater Biology, 46, 1811-1831.

Chertoprud, M. V., Palatov, D. M., \& Dimante-Deimantovica, I. (2017). Macrobenthic communities in water bodies and streams of Svalbard, Norway. Journal of Natural History, 51(47-48), 2809-2825. doi:10.1080/00222933.2017.1395092

Chin, K. S., Lento, J., Culp, J. M., Lacelle, D., \& Kokelj, S. V. (2016). Permafrost thaw and intense thermokarst activity decreases abundance of stream benthic macroinvertebrates. Global Change Biology, 22(8), 2715-2728. doi:10.1111/gcb.13225

Christiansen, J. S., Reist, J. D., Brown, R. J., Brykov, V. A., Christensen, G., Christoffersen, K. S., . . Wrona, F. J. (2013). Chapter 6: Fishes. In H. Meltofte (Ed.), Arctic Biodiversity Assessment. Status and Trends in Arctic Biodiversity (pp. 193-245). Akureyri, Iceland: Conservation of Arctic Flora and Fauna (CAFF) 
Chu, C., Mandrak, N. E., \& Minns, C. K. (2005). Potential impacts of climate change on the distributions of several common and rare freshwater fishes in Canada. Diversity and Distributions, 11(4), 299-310.

Colwell, R. K. (2013). EstimateS: Statistical estimation of species richness and shared species from samples. Version 9. User's Guide and application published at: http://purl.oclc.org/estimates.

Colwell, R. K., Chao, A., Gotelli, N. J., Lin, S.-Y., Mao, C. X., Chazdon, R. L., \& Longino, J. T. (2012). Models and estimators linking individual-based and sample-based rarefaction, extrapolation and comparison of assemblages. Journal of plant ecology, 5(1), 3-21.

Colwell, R. K., \& Elsensohn, J. E. (2014). EstimateS turns 20: statistical estimation of species richness and shared species from samples, with non-parametric extrapolation. Ecography, 37(6), 609-613.

Colwell, R. K., Mao, C. X., \& Chang, J. (2004). Interpolating, extrapolating, and comparing incidence-based species accumulation curves. Ecology, 85(10), 2717-2727.

Culp, J. M., Goedkoop, W., Lento, J., Christoffersen, K. S., Frenzel, S., Guðbergsson, G., . . . Whitman, M. (2012). The Arctic Freshwater Biodiversity Monitoring Plan (CAFF Monitoring Series Report Nr. 7). Retrieved from CAFF International Secretariat: https://caff.is/freshwater

Culp, J. M., Lento, J., Curry, R. A., Luiker, E., \& Halliwell, D. (2019). Arctic river biodiversity declines in response to latitudinal change in the abiotic template. Freshwater Science, 38(3), 465-479. doi:10.1086/704887

Culp, J. M., Lento, J., Goedkoop, W., Power, M., Rautio, M., Christoffersen, K. S., ... Svoboda, M. (2012). Developing a circumpolar monitoring framework for Arctic freshwater biodiversity. Biodiversity, 13(3-4), 215-227.

Danks, H. V. (2007). How aquatic insects live in cold climates. The Canadian Entomologist, 139(4), 443-471. 
Dias, M. S., Oberdorff, T., Hugueny, B., Leprieur, F., Jézéquel, C., Cornu, J. F., . . Tedesco, P. A. (2014). Global imprint of historical connectivity on freshwater fish biodiversity. Ecology Letters, 17(9), 1130-1140.

Domisch, S., Araújo, M. B., Bonada, N., Pauls, S. U., Jähnig, S. C., \& Haase, P. (2013). Modelling distribution in European stream macroinvertebrates under future climates. Global Change Biology, 19, 752-762.

Dudgeon, D., Arthington, A. H., Gessner, M. O., Kawabata, Z.-I., Knowler, D. J., Lévêque, C., . . . Stiassny, M. L. (2006). Freshwater biodiversity: importance, threats, status and conservation challenges. Biological Reviews, 81(2), 163-182.

Dunmall, K. M., Mochnacz, N. J., Zimmerman, C. E., Lean, C., \& Reist, J. D. (2016). Using thermal limits to assess establishment of fish dispersing to high-latitude and highelevation watersheds. Canadian Journal of Fisheries and Aquatic Sciences, 73(12), 1750-1758.

Dyke, A., Moore, A., \& Robertson, L. (2003). Deglaciation of North America: Geological Survey of Canada Open File 1574. Retrieved from: https://doi.org/10.4095/214399

Environment Canada. (2012). Canadian Aquatic Biomonitoring Network Field Manual Wadeable Streams. Retrieved from Government of Canada Publications: http://publications.gc.ca/pub?id=9.696248\&sl=0

Environment Canada. (2014). Canadian Aquatic Biomonitoring Network Laboratory Methods: processing, taxonomy, and quality control of benthic macroinvertebrate samples. Retrieved from Government of Canada Publications: http://publications.gc.ca/pub?id=9.700149\&sl=0

Fox, J., \& Weisberg, S. (2019). An \{R\} Companion to Applied Regression, Third Edition. Thousand Oaks, CA: Sage. Retrieved from https://socialsciences.mcmaster.ca/jfox/Books/Companion/ 
Friberg, N., Milner, A. M., Svendsen, L. M., Lindegaard, C., \& Larsen, S. E. (2001).

Macroinvertebrate stream communities along regional and physico-chemical gradients in Western Greenland. Freshwater Biology, 46, 1753-1764.

Garrity, C. P., \& Soller, D. R. (2009). Database of the Geologic Map of North America-Adapted from the Map by JC Reed, Jr. and others (2005). U.S. Geological Survey Data Series 424. Retrieved from: https://pubs.usgs.gov/ds/424/

Grenier, M., Campeau, S., Lavoie, I., Park, Y. S., \& Lek, S. (2006). Diatom reference communities in Quebec (Canada) streams based on Kohonen self-organizing maps and multivariate analyses. Canadian Journal of Fisheries and Aquatic Sciences, 63(9), 20872106.

Griffiths, D. (2010). Pattern and process in the distribution of North American freshwater fish. Biological Journal of the Linnean Society, 100(1), 46-61.

Griffiths, D. (2015). Connectivity and vagility determine spatial richness gradients and diversification of freshwater fish in North America and Europe. Biological Journal of the Linnean Society, 116(4), 773-786.

Guo, F., Bunn, S. E., Brett, M. T., \& Kainz, M. J. (2017). Polyunsaturated fatty acids in stream food webs-high dissimilarity among producers and consumers. Freshwater Biology, 62(8), 1325-1334.

Hamilton, P. B., Gajewski, K., Atkinson, D. E., \& Lean, D. R. (2001). Physical and chemical limnology of 204 lakes from the Canadian Arctic Archipelago. Hydrobiologia, 457(1-3), 133-148.

Havas, M., \& Rosseland, B. O. (1995). Response of zooplankton, benthos, and fish to acidification: an overview. Water, Air, and Soil Pollution, 85, 51-62.

Heino, J. (2011). A macroecological perspective of diversity patterns in the freshwater realm. Freshwater Biology, 56(9), 1703-1722. 
Heino, J. (2014). Taxonomic surrogacy, numerical resolution and responses of stream macroinvertebrate communities to ecological gradients: are the inferences transferable among regions? Ecological Indicators, 36, 186-194.

Heino, J., Culp, J. M., Erkinaro, J., Goedkoop, W., Lento, J., Rühland, K. M., \& Smol, J. P. (2020). Abruptly and irreversibly changing Arctic freshwaters urgently require standardized monitoring. Journal of Applied Ecology. doi:10.1111/1365-2664.13645

Heino, J., Virkkala, R., \& Toivonen, H. (2009). Climate change and freshwater biodiversity: detected patterns, future trends and adaptations in northern regions. Biological Reviews, 84, 39-54.

Hillebrand, H. (2004). On the generality of the latitudinal diversity gradient. American Naturalist, $163,192-211$.

Huser, B. J., Futter, M. N., Bogan, D., Brittain, J. E., Culp, J. M., Goedkoop, W., . . Lento, J. (In Review). Spatial and temporal variation in Arctic freshwater chemistry - reflecting climate-induced landscape alterations and a changing template for biodiversity. Freshwater Biology.

IPCC. (2014). Climate Change 2014: Synthesis Report. Contribution of Working Groups I, II and III to the fifth assessment report of the Intergovernmental Panel on Climate Change (Core Writing Team, R. K. Pachauri, \& L. A. Meyer Eds.). Geneva, Switzerland: IPCC. Irons III, J. G., Miller, L. K., \& Oswood, M. W. (1993). Ecological adaptations of aquatic macroinvertebrates to overwintering in interior Alaska (USA) subarctic streams. Canadian Journal of Zoology, 71(1), 98-108.

Jackson, D. A. (1995). PROTEST: A PROcrustean Randomization TEST of community environment concordance. Ecoscience, 2(3), 297-303.

Jackson, D. A., Peres-Neto, P. R., \& Olden, J. D. (2001). What controls who is where in freshwater fish communities the roles of biotic, abiotic, and spatial factors. Canadian Journal of Fisheries and Aquatic Sciences, 58(1), 157-170. 
Jacobsen, D., \& Dangles, O. (2012). Environmental harshness and global richness patterns in glacier-fed streams. Global Ecology and Biogeography, 21, 647-656.

Kahlert, M., Rühland, K. M., Lavoie, I., Keck, F., Saulnier-Talbot, É., Bogan, D., . . Smol, J. P. (2020). Spatial and temporal patterns of circum-Arctic lake and stream diatom assemblages: Establishing current reference conditions and historical context for biomonitoring. Freshwater Biology, 00, 1-25. doi:10.1111/fwb.13490

Kendrick, M. R., Hershey, A. E., \& Huryn, A. D. (2019). Disturbance, nutrients, and antecedent flow conditions affect macroinvertebrate community structure and productivity in an Arctic river. Limnology and Oceanography, 64(S1), S93-S104.

Kristiansen, J. (1996). Biogeography of freshwater algae-conclusions and perspectives. In J. Kristiansen (Ed.), Biogeography of Freshwater Algae (pp. 159-161). Dordrecht: Springer.

Laske, S., Amundsen, P.-A., Christoffersen, K. S., Erkinaro, J., Guðbergsson, G., Hayden, B., . . . Zimmerman, C. E. (2019). Circumpolar patterns of Arctic freshwater fish biodiversity: a baseline for monitoring. Freshwater Biology, 00, 1-19. doi:10.1111/fwb.13405

Laske, S., Haynes, T. B., Rosenberger, A. E., Koch, J. C., Wipfli, M. S., Whitman, M., \& Zimmerman, C. E. (2016). Surface water connectivity drives richness and composition of Arctic lake fish assemblages. Freshwater Biology, 61(7), 1090-1104.

Legendre, P., \& Gallagher, E. D. (2001). Ecologically meaningful transformations for ordination of species data. Oecologia, 129(2), 271-280.

Lehner, B., \& Grill, G. (2013). Global river hydrography and network routing: baseline data and new approaches to study the world's large river systems. Hydrological Processes, 27(15), 2171-2186.

Lento, J., Culp, J. M., Levenstein, B., Aroviita, J., Baturina, M. A., Bogan, D., . . Goedkoop, W. (In Review). Temperature and spatial connectivity drive benthic macroinvertebrate biodiversity across Arctic lakes and rivers. Freshwater Biology. 
Lento, J., Goedkoop, W., Culp, J., Christoffersen, K., Fefilova, E., Guðbergsson, G., .. . Svenning, M. (2019). State of the Arctic Freshwater Biodiversity Report. Retrieved from Conservation of Arctic Flora and Fauna (CAFF) International Secretariat: caff.is/freshwater

Lento, J., Monk, W. A., Culp, J. M., Curry, R. A., Cote, D., \& Luiker, E. (2013). Responses of low Arctic stream benthic macroinvertebrate communities to environmental drivers at nested spatial scales. Arctic, Antarctic, and Alpine Research, 45(4), 538-551.

Levenstein, B., Culp, J., \& Lento, J. (2018). Sediment Inputs from retrogressive thaw slumps drive algal biomass accumulation but not decomposition in Arctic streams, NWT. Freshwater Biology, 63(10), 1300-1315. doi:10.1111/fwb.13158

Lürling, M., Mello, M. M., van Oosterhout, F., de Senerpont Domis, L., \& Marinho, M. M. (2018). Response of natural cyanobacteria and algae assemblages to a nutrient pulse and elevated temperature. Frontiers in microbiology, 9.

Michelutti, N., Douglas, M. S. V., \& Smol, J. P. (2003). Diatom response to recent climatic change in a high arctic lake (Char Lake, Cornwallis Island, Nunavut). Global and Planetary Change, 38(3-4), 257-271.

Milner, A. M., Brittain, J. E., Castella, E., \& Petts, G. E. (2001). Trends of macroinvertebrate community structure in glacier-fed rivers in relation to environmental conditions: a synthesis. Freshwater Biology, 46, 1833-1847.

Milner, A. M., \& Petts, G. E. (1994). Glacial rivers: physical habitat and ecology. Freshwater Biology, 32, 295-307.

Neff, M. R., \& Jackson, D. A. (2013). Regional-scale patterns in community concordance: testing the roles of historical biogeography versus contemporary abiotic controls in determining stream community composition. Canadian Journal of Fisheries and Aquatic Sciences, 70(8), 1141-1150. 
Nelson, M. L., Rhoades, C. C., \& Dwire, K. A. (2011). Influence of Bedrock Geology on Water Chemistry of Slope Wetlands and Headwater Streams in the Southern Rocky Mountains. Wetlands, 31(2), 251-261. doi:10.1007/s13157-011-0157-8

Oksanen, J., Blanchet, F. G., Kindt, R., Legendre, P., Minchin, P. R., O'Hara, R. B., ... Wagner, H. (2015). Vegan: Community Ecology Package. R package version 2.3-2. Retrieved from https://CRAN.R-project.org/package=vegan

Olson, D. M., Dinerstein, E., Wikramanayake, E. D., Burgess, N. D., Powell, G. V. N., Underwood, E. C., . . . Kassem, K. R. (2001). Terrestrial ecoregions of the world: a new map of life on Earth. BioScience, 51(11), 933-938.

Oswood, M., Reynolds, J., Irons III, J., \& Milner, A. (2000). Distributions of freshwater fishes in ecoregions and hydroregions of Alaska. Journal of the North American Benthological Society, 19(3), 405-418.

Paerl, H. W., \& Paul, V. J. (2012). Climate change: links to global expansion of harmful cyanobacteria. Water Research, 46(5), 1349-1363.

Poff, N. L. (1997). Landscape filters and species traits: towards mechanistic understanding and prediction in stream ecology. Journal of the North American Benthological Society, 16(2), 391-409.

Potapova, M., \& Charles, D. F. (2003). Distribution of benthic diatoms in US rivers in relation to conductivity and ionic composition. Freshwater Biology, 48(8), 1311-1328.

Power, G. (2002). Charrs, glaciations and seasonal ice. In Ecology, behaviour and conservation of the charrs, genus Salvelinus (pp. 17-35): Springer.

Power, M., Reist, J. D., \& Dempson, J. B. (2008). Fish in high-latitude Arctic lakes. In W. F. Vincent \& J. Laybourn-Parry (Eds.), Polar lakes and rivers (pp. 249-267). Oxford, UK: Oxford University Press. 
Prowse, T. D., Alfredsen, K., Beltaos, S., Bonsal, B. R., Bowden, W. B., Duguay, C. R., . . Weyhenmeyer, G. A. (2011). Effects of changes in Arctic lake and river ice. Ambio, 40, $63-74$

Prowse, T. D., Wrona, F. J., Reist, J. D., Gibson, J. J., Hobbie, J. E., Lévesque, L. M. J., \& Vincent, W. F. (2006a). Climate change effects on hydroecology of Arctic freshwater ecosystems. Ambio, 35(7), 347-358.

Prowse, T. D., Wrona, F. J., Reist, J. D., Gibson, J. J., Hobbie, J. E., Lévesque, L. M. J., \& Vincent, W. F. (2006b). Historical changes in Arctic freshwater ecosystems. Ambio, 35(7), 339-346.

R Development Core Team. (2015). R: A Language and Environment for Statistical Computing. In. Retrieved from http://www.R-project.org

Reimann, C., Finne, T. E., Nordgulen, Ø., Sæther, O. M., Arnoldussen, A., \& Banks, D. (2009). The influence of geology and land-use on inorganic stream water quality in the Oslo region, Norway. Applied Geochemistry, 24(10), 1862-1874.

Reist, J. D., Wrona, F. J., Prowse, T. D., Power, M., Dempson, J. B., Beamish, R. J., . . . Sawatzky, C. D. (2006). General effects of climate change on Arctic fishes and fish populations. Ambio, 35, 370-380.

Rolls, R. J., Heino, J., Ryder, D. S., Chessman, B. C., Growns, I. O., Thompson, R. M., \& Gido, K. B. (2018). Scaling biodiversity responses to hydrological regimes. Biological Reviews, 93(2), 971-995.

Rouse, W. R., Douglas, M. S., Hecky, R. E., Hershey, A. E., Kling, G. W., Lesack, L., . . . Roulet, N. T. (1997). Effects of climate change on the freshwaters of arctic and subarctic North America. Hydrological Processes, 11(8), 873-902.

Sala, O. E., Chapin, F. S., Armesto, J. J., Berlow, E., Bloomfield, J., Dirzo, R., . . Kinzig, A. (2000). Global biodiversity scenarios for the year 2100. Science, 287(5459), 1770-1774. 
Schindler, D. W., \& Smol, J. P. (2006). Cumulative effects of climate warming and other human activities on freshwaters of Arctic and subarctic North America. AMBIO: A Journal of the Human Environment, 35(4), 160-168.

Schleuter, D., Daufresne, M., Veslot, J., Mason, N. W., Lanoiselée, C., Brosse, S., ... Argillier, C. (2012). Geographic isolation and climate govern the functional diversity of native fish communities in European drainage basins. Global Ecology and Biogeography, 21(11), 1083-1095.

Schmidt, K., \& Jónasdóttir, S. H. (1997). Nutritional quality of two cyanobacteria: How rich is 'poor' food? Marine Ecology Progress Series, 151, 1-10.

Scott, R. W., Barton, D. R., Evans, M. S., \& Keating, J. J. (2011). Latitudinal gradients and local control of aquatic insect richness in a large river system in northern Canada. Journal of the North American Benthological Society, 30, 621-634.

Scott, W., \& Crossman, E. (1973). Freshwater fishes of Canada: Fisheries Research Board of Canada Bulletin, Vol. 184. Fisheries Research Board of Canada, Ottawa.

Serreze, M. C., \& Barry, R. G. (2011). Processes and impacts of Arctic amplification: A research synthesis. Global and Planetary Change, 77(1-2), 85-96.

Shah, D. N., Domisch, S., Pauls, S. U., Haase, P., \& Jähnig, S. C. (2014). Current and future latitudinal gradients in stream macroinvertebrate richness across North America. Freshwater Science, 33(4), 1136-1147.

Sinnatamby, R. N., Shears, M., Dempson, J. B., \& Power, M. (2013). Thermal habitat use and growth in young-of-the-year Arctic charr from proximal fluvial and lacustrine populations in Labrador, Canada. Journal of Thermal Biology, 38(8), 493-501.

Slavik, K., Peterson, B., Deegan, L., Bowden, W., Hershey, A. E., \& Hobbie, J. (2004). LongTerm Responses Of The Kuparuk River Ecosystem To Phosphorus Fertilization. Ecology, 85(4), 939-954. 
Socolar, J. B., Gilroy, J. J., Kunin, W. E., \& Edwards, D. P. (2016). How should beta-diversity inform biodiversity conservation? Trends in Ecology \& Evolution, 31(1), 67-80.

ter Braak, C. J. F., \& Šmilauer, P. (2002). Reference Manual and User's Guide to CANOCO for Windows (version 4.5). Wageningen: Center for Biometry.

Valett, H. M., Morrice, J. A., Dahm, C. N., \& Campana, M. E. (1996). Parent lithology, surfacegroundwater exchange, and nitrate retention in headwater streams. Limnology and Oceanography, 41(2), 333-345.

Van Dam, H., Mertens, A., \& Sinkeldam, J. (1994). A coded checklist and ecological indicator values of freshwater diatoms from the Netherlands. Netherland Journal of Aquatic Ecology, 28(1), 117-133.

Vincent, W. F., Callaghan, T. V., Dahl-Jensen, D., Johansson, M., Kovacs, K. M., Michel, C., ... Sharp, M. (2011). Ecological implications of changes in the Arctic cryosphere. Ambio, 40, 87-91.

Vincent, W. F., \& Laybourn-Parry, J. (2008). Polar lakes and rivers: limnology of Arctic and Antarctic aquatic ecosystems: Oxford university press.

Vinson, M. R., \& Hawkins, C. P. (2003). Broad-scale geographical patterns in local stream insect genera richness. Ecography, 26, 751-767.

Wentworth, C. K. (1922). A scale of grade and class terms for clastic sediments. The journal of geology, 30(5), 377-392.

Wrona, F. J., Johansson, M., Culp, J. M., Jenkins, A., Mård, J., Myers-Smith, I. H., . . W Wookey, P. A. (2016). Transitions in Arctic ecosystems: Ecological implications of a changing hydrological regime. Journal of Geophysical Research: Biogeosciences, 121(3), 650674. doi:10.1002/2015JG003133

Wrona, F. J., Prowse, T. D., Reist, J. D., Hobbie, J. E., Lévesque, L. M. J., \& Vincent, W. F. (2006). Climate change effects on aquatic biota, ecosystem structure and function. Ambio, 35(7), 359-369. 
Wrona, F. J., Reist, J. D., Amundsen, P.-A., Chambers, P. A., Christoffersen, K. S., Culp, J. M., ... Zavalko, S. (2013). Chapter 13: Freshwater Ecosystems. In H. Meltofte (Ed.), Arctic Biodiversity Assessment. Status and Trends in Arctic Biodiversity (pp. 335-377). Akureyri, Iceland: Conservation of Arctic Flora and Fauna (CAFF) 


\section{Tables}

Table 1. Environmental variables used in analyses, including $(A)$ geospatial layers (with sources), variables extracted for alpha diversity analysis, and the drivers that they represented; (B) field-measured variables used for multi-FEC analysis, including water chemistry and substrate size; and (C) geospatial layers (with sources), variables extracted for multi-FEC analysis, and the drivers that they represented. Variables in italics in (B) and (C) were retained for analysis.

A.

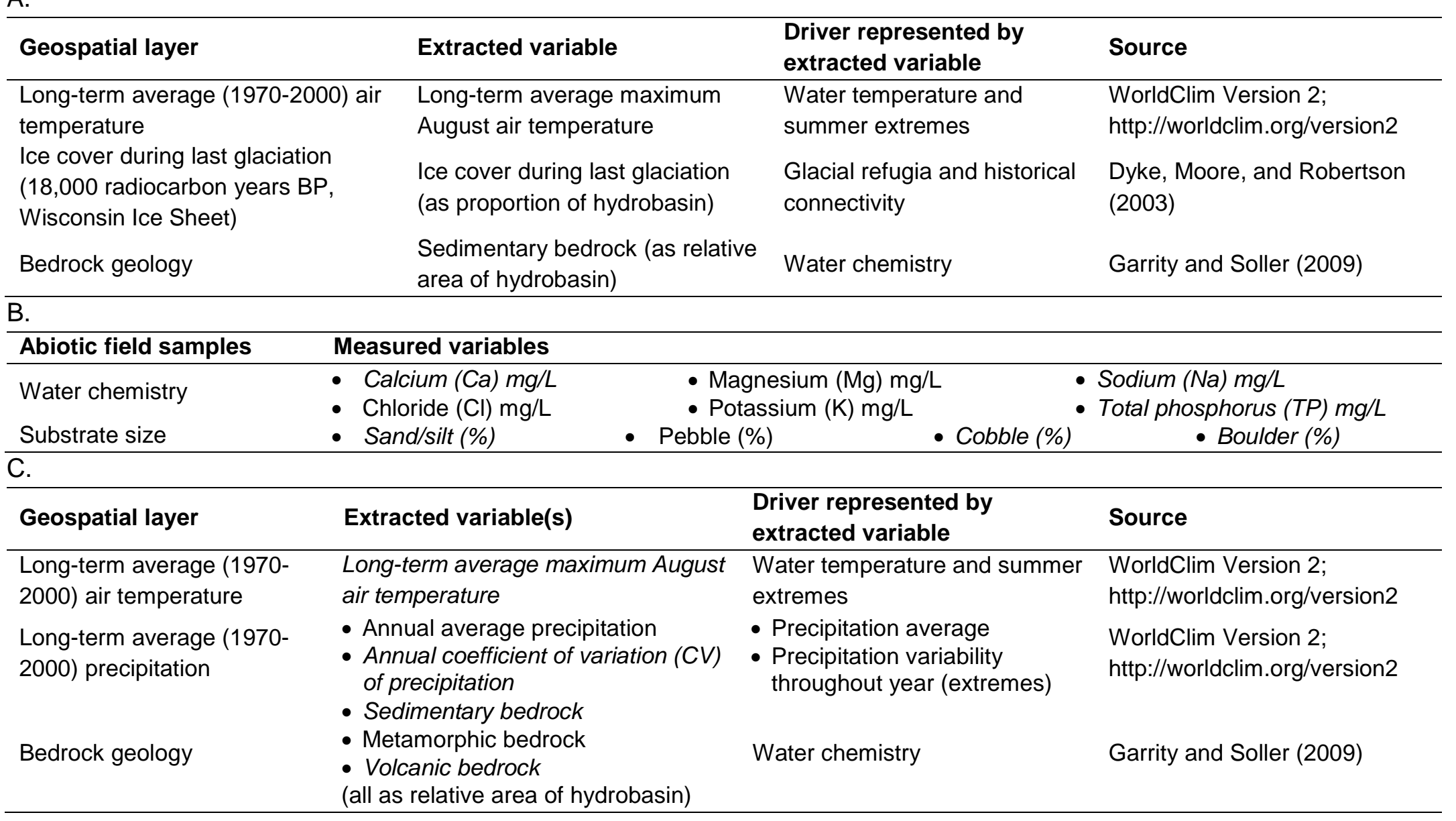


Table 2. Response of diatom, benthic macroinvertebrate, and fish alpha diversity to gradients of latitude,

temperature (long-term average maximum August air temperature), physical geography (percent of the basin with ice cover in the last glaciation), and bedrock geology (relative area of sedimentary bedrock in the basin), indicating the range for each environmental correlate and the change in biodiversity (increase, decrease, or no change) with an increase in the correlate. Change in diversity as indicated in the table for temperature,

physical geography, and bedrock geology reflects the results of multiple linear regression analysis and the final models chosen for each functional ecosystem component (FEC).

\begin{tabular}{|c|c|c|c|c|c|c|c|c|}
\hline \multirow[b]{3}{*}{ FEC } & \multicolumn{8}{|c|}{ Environmental Correlate } \\
\hline & \multicolumn{2}{|l|}{ Latitude } & \multicolumn{2}{|c|}{ Temperature } & \multicolumn{2}{|c|}{ Physical geography } & \multicolumn{2}{|l|}{ Bedrock geology } \\
\hline & $\begin{array}{l}\text { Range } \\
(\text { deg N) }\end{array}$ & $\begin{array}{l}\text { Change in } \\
\text { diversity }\end{array}$ & $\begin{array}{l}\text { Range } \\
\text { (deg C) }\end{array}$ & $\begin{array}{l}\text { Change in } \\
\text { diversity }\end{array}$ & $\begin{array}{l}\text { Range (\% } \\
\text { glaciation cover) }\end{array}$ & $\begin{array}{l}\text { Change in } \\
\text { diversity }\end{array}$ & $\begin{array}{l}\text { Range (rel. area } \\
\text { sedimentary) }\end{array}$ & $\begin{array}{l}\text { Change in } \\
\text { diversity }\end{array}$ \\
\hline Diatoms & $58-82$ & $\begin{array}{l}\text { No } \\
\text { change }\end{array}$ & $4.5-14.7$ & Increase & $0-100$ & $\begin{array}{l}\text { No } \\
\text { change }\end{array}$ & $0.002-0.998$ & Increase \\
\hline $\begin{array}{l}\text { Benthic } \\
\text { macroinvertebrates }\end{array}$ & $50-82$ & Decrease & $4.5-19.3$ & Increase & $0-100$ & $\begin{array}{l}\text { No } \\
\text { change }\end{array}$ & 0.013-0.998 & No change \\
\hline Fish & $62-72$ & Increase ${ }^{a}$ & $9.4-16.7$ & No change & $0-100$ & Decrease $^{b}$ & $0.698-1.000$ & No change \\
\hline
\end{tabular}

aLimited latitudinal range, regional increase

bStrongest model, but similar AICc to null model 
Table 3. Results of significance tests for environmental variables included in diatom and benthic macroinvertebrate RDAs, including Lambda-A (conditional effects), F-ratios, and p for each variable. Variables are listed in order of decreasing conditional effects, and p-values that are significant at $\alpha=0.05$ are in bold.

\begin{tabular}{|c|c|c|c|c|c|c|c|}
\hline Diatoms & $\begin{array}{c}\text { Lambda- } \\
\text { A }\end{array}$ & $\boldsymbol{F}$ & $p$ & $\begin{array}{l}\text { Benthic } \\
\text { macro- } \\
\text { invertebrate }\end{array}$ & $\begin{array}{c}\text { Lambda- } \\
\text { A }\end{array}$ & $F$ & $p$ \\
\hline $\mathrm{Ca}$ & 0.11 & 15.89 & 0.002 & PrecipCV & 0.19 & 29.27 & 0.002 \\
\hline SandSilt & 0.1 & 15.83 & 0.002 & Sedimentary & 0.06 & 11.44 & 0.002 \\
\hline MaxAugTemp & 0.03 & 5.58 & 0.002 & SandSilt & 0.05 & 8.7 & 0.002 \\
\hline Sedimentary & 0.03 & 4.68 & 0.002 & Volcanic & 0.02 & 3.98 & 0.002 \\
\hline PrecipCV & 0.02 & 3.45 & 0.002 & MaxAugTemp & 0.02 & 3.03 & 0.006 \\
\hline Volcanic & 0.02 & 3.21 & 0.004 & $\mathrm{Ca}$ & 0.01 & 2.48 & 0.016 \\
\hline TP & 0.01 & 2.18 & 0.004 & Boulder & 0.01 & 1.63 & 0.11 \\
\hline $\mathrm{Na}$ & 0.01 & 2.05 & 0.012 & TP & 0.01 & 1.28 & 0.224 \\
\hline Cobble & 0.01 & 1.59 & 0.046 & $\mathrm{Na}$ & 0.01 & 1.02 & 0.378 \\
\hline Boulder & 0.01 & 1.42 & 0.108 & Cobble & 0 & 1.27 & 0.242 \\
\hline
\end{tabular}




\section{Figure Captions}

Fig. 1. (A) Ecoregions (shaded regions) and level 05 Hydrobasins (black hashed areas) used to group sites for analysis of alpha diversity, (B) distribution of all diatom, benthic macroinvertebrate, and fish sites and (C) multi-FEC sites across North America. The red line indicates the CAFF boundary (source: caff.is), which was the approximate southern boundary for inclusion of samples. Ecoregion layer from Olson et al. (2001), Hydrobasin layer from Lehner \& Grill (2013), and geopolitical boundaries from Natural Earth (www.naturalearthdata.com).

Fig. 2. Large-scale environmental drivers in the North American Arctic, including (A) long-term (1970-2000) average maximum August air temperature (source: WorldClim Version 2; worldclim.org/version2), (B) ice cover during the last glaciation (180k BP; Wisconsin Ice Sheet; Dyke et al., 2003), and (C) underlying bedrock geology, classified by type (Garrity \& Soller, 2009). Geopolitical boundaries layer from Natural Earth (www.naturalearthdata.com).

Fig. 3. Rarefied alpha diversity (estimated at 10 sites \pm standard deviation) at the hydrobasin/ecoregion intersection scale plotted as a function of the average latitude of sites in each hydrobasin/ecoregion intersection for (A) diatoms, $(B)$ benthic macroinvertebrates, and (C) fish, with points coloured based on ecoregion location. Triangles indicate hydrobasins in western North America and circles indicate hydrobasins in eastern North America. Only hydrobasin/ecoregion intersections with $>3$ sites are plotted.

Fig. 4. Scatterplots of alpha diversity at the hydrobasin/ecoregion intersection scale as a function of environmental correlates with linear regression lines, including $(A) \log _{10}$ diatom diversity as a function of LTA maximum August air temperature while holding geology constant, (B) $\log _{10}$ diatom diversity as a function of logit relative abundance of sedimentary bedrock while holding temperature constant, (C) $\log _{10}$ fish diversity plotted as a function of the relative area of 
ice cover during the last glaciation, and (D) $\log _{10}$ macroinvertebrate diversity in eastern North American hydrobasins and (E) $\log _{10}$ macroinvertebrate diversity in western North American hydrobasins, both plotted as a function of LTA maximum August air temperature.

Fig. 5. PCA ordinations of (A) fish data at species level and (B) benthic macroinvertebrate data at order level for western North American Arctic sites in Canada (blue triangles) and Alaska (orange upside-down triangles). Percent variance explained by each axis is indicated in axis labels and taxon points are labelled with codes. Fish taxon codes: Alaska blackfish (ALBL), Arctic char (CHAR), Arctic cisco (ARCIS), Arctic grayling (ARGRY), broad whitefish (BWHT), bull trout (BULLT), burbot (BURB), humpback whitefish (HUMPW), inconnu (INCON), lake chub (LKCHB), lake trout (LKTRT), lake whitefish (LKWHT), least cisco (LSCIS), longnose sucker (LNGSCK), ninespine stickleback (9STK), pike (PIKE), round whitefish (RWHT), slimy sculpin (SSCUL), white sucker (WHTSCK). Benthic macroinvertebrate taxon codes: Chironomidae (CHIR), non-Chironomidae Diptera (DIPT), Coleoptera (COL), Ephemeroptera (EPHEM), Mollusca (MOLL), Oligochaeta (OLIG), Plecoptera (PLEC), Trichoptera (TRICH).

Fig. 6. PCA ordinations of (A) Hellinger-transformed diatom relative abundance data at adjusted species level and (B) Hellinger-transformed benthic macroinvertebrate relative abundance data at family level for sites across eastern and western North America where both diatoms and benthic macroinvertebrates were sampled. Taxa are indicated by hollow circles, and sites are indicated by coloured shapes as described in the legend. Percent variance explained by each axis is shown in the axis label. Dominant diatom genera/species (groupings of species and species complexes used in the analysis) in different areas of the ordination are indicated in (A), whereas (B) shows labeled taxon points for some benthic macroinvertebrate (taxa near the origin unlabelled for ease of interpretation). Benthic macroinvertebrate taxon codes: Acari (Acari), Ceratopogonidae (D_Cerat), Chironomidae (D_Chir), Empididae (D_Emp), Simuliidae 
(D_Simu), Tipulidae (D_Tipu), Coleoptera (Coleopt), Ameletidae (E_Amel), Baetidae (E_Bae), Ephemerellidae (E_Ephe), Heptageniidae (E_Hept), Lymnaeidae (Gas_Lym), Oligochaeta (Oligo), Capniidae (P_Cap), Chloroperlidae (P_Chl), Nemouridae (P_Nem), Perlodidae (P_Perlo), Apataniidae (T_Apat), Glossosomatidae (T_Glos), Hydropsychidae (T_Hpsy), Hydroptilidae (T_Hpti), Rhyacophilidae (T_Rhya).

Fig. 7. RDA ordinations of (A) Hellinger-transformed diatom relative abundance data at adjusted species level and (B) Hellinger-transformed benthic macroinvertebrate relative abundance data at family level for sites across eastern and western North America where both diatoms and benthic macroinvertebrates were sampled, with biotic data constrained by the same set of environmental variables. Taxa are indicated by unlabelled hollow circles, and sites are indicated by coloured symbols as indicated in the legend. Percent variance in the assemblages (unconstrained variance) explained by each axis is shown in the axis label.

\section{Supplementary Figure Captions}

Figure S1. Flow chart indicating the analysis steps for alpha diversity and multi-FEC analysis for diatoms, benthic macroinvertebrates, and fish in North American Arctic rivers. Steps in bold are final analyses, and the number of stations (n) is indicated for each analysis.

Figure S2. PCA ordination (axes I and III) of Hellinger-transformed BMI relative abundance data at family level for stations across eastern and western North America where both diatoms and BMI were sampled. Taxa are indicated by hollow circles, and stations are indicated by coloured shapes as described in the legend. Percent variance explained by each axis is shown in the axis label. BMI taxon codes: Acari (Acari), Ceratopogonidae (D_Cerat), Chironomidae (D_Chir), Empididae (D_Emp), Muscidae (D_Mus), Simuliidae (D_Simu), Tipulidae (D_Tipu), Coleoptera (Coleopt), Ameletidae (E_Amel), Baetidae (E_Bae), Ephemerellidae (E_Ephe), Heptageniidae 
(E_Hept), Lymnaeidae (Gas_Lym), Physidae (Gas_Phy), Planorbidae (Gas_Plan), Valvatidae (Gas_Val), Oligochaeta (Oligo), Capniidae (P_Cap), Chloroperlidae (P_Chl), Nemouridae (P_Nem), Perlodidae (P_Perlo), Pisidiidae (Pisid), Apataniidae (T_Apat), Brachycentridae (T_Bra), Glossosomatidae (T_Glos), Hydropsychidae (T_Hpsy), Hydroptilidae (T_Hpti), Limnephilidae (T_Limn), Phryganeidae (T_Phry), Rhyacophilidae (T_Rhya). 

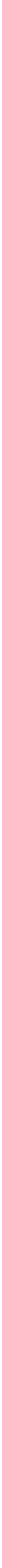


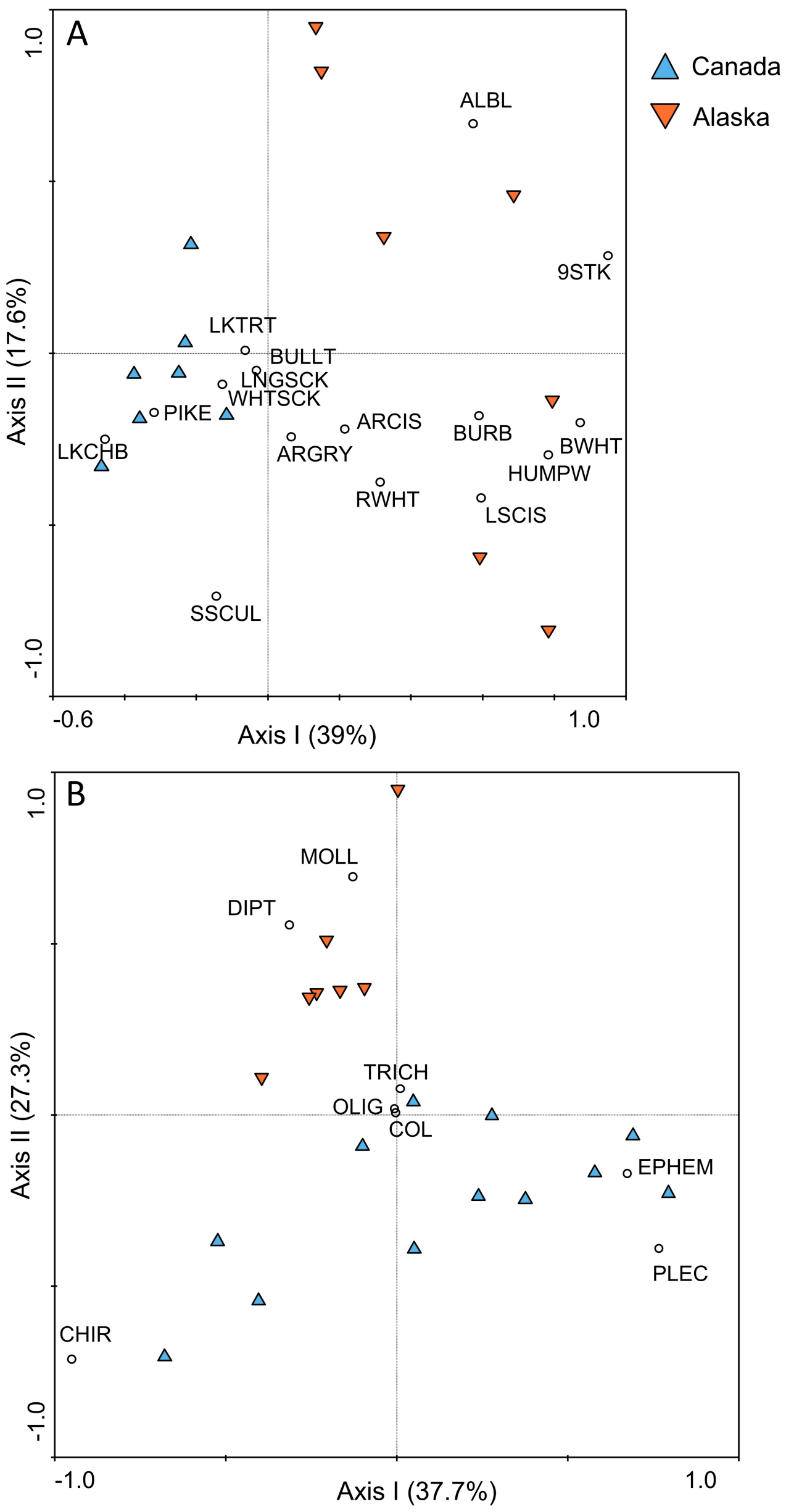


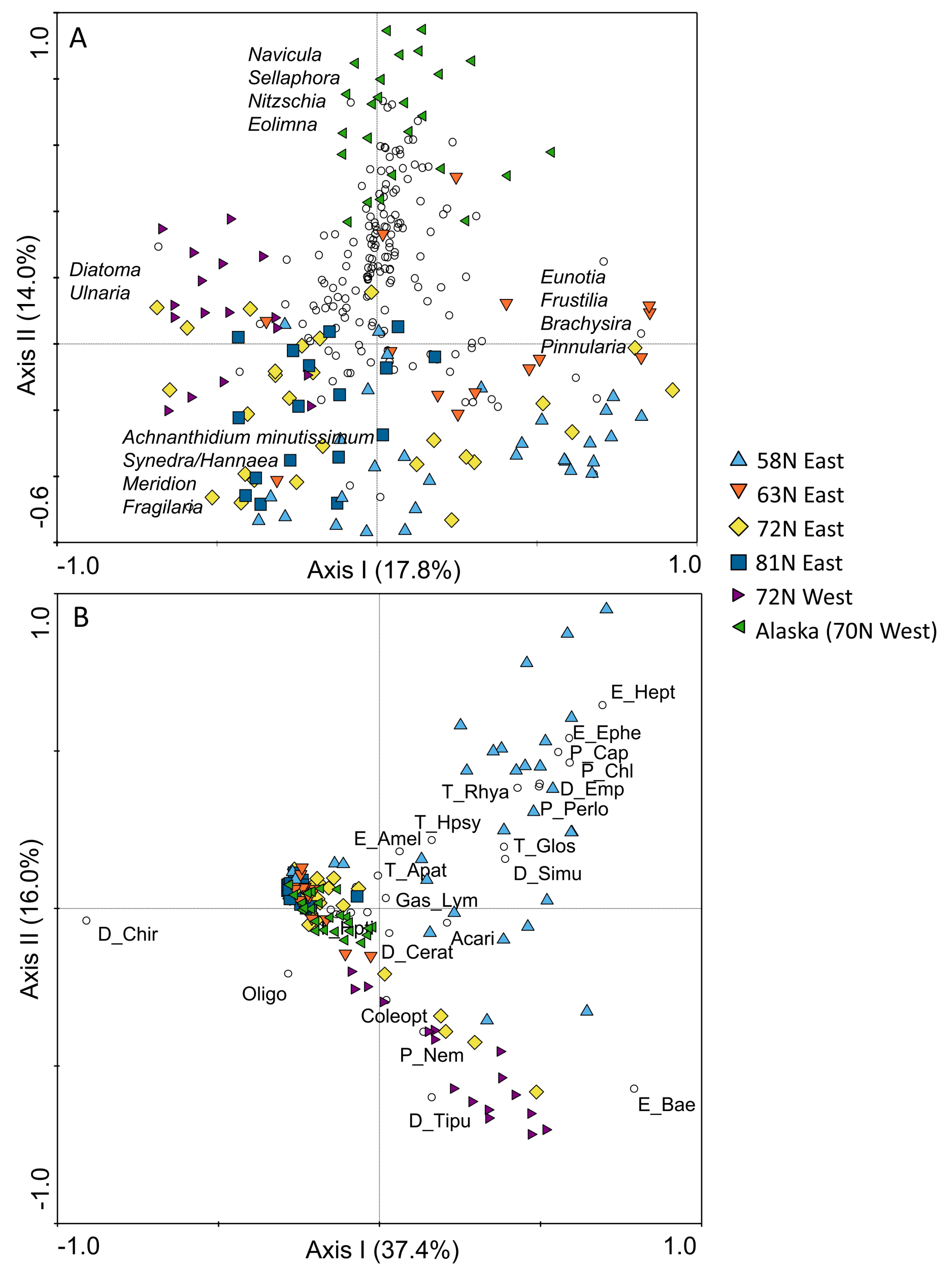



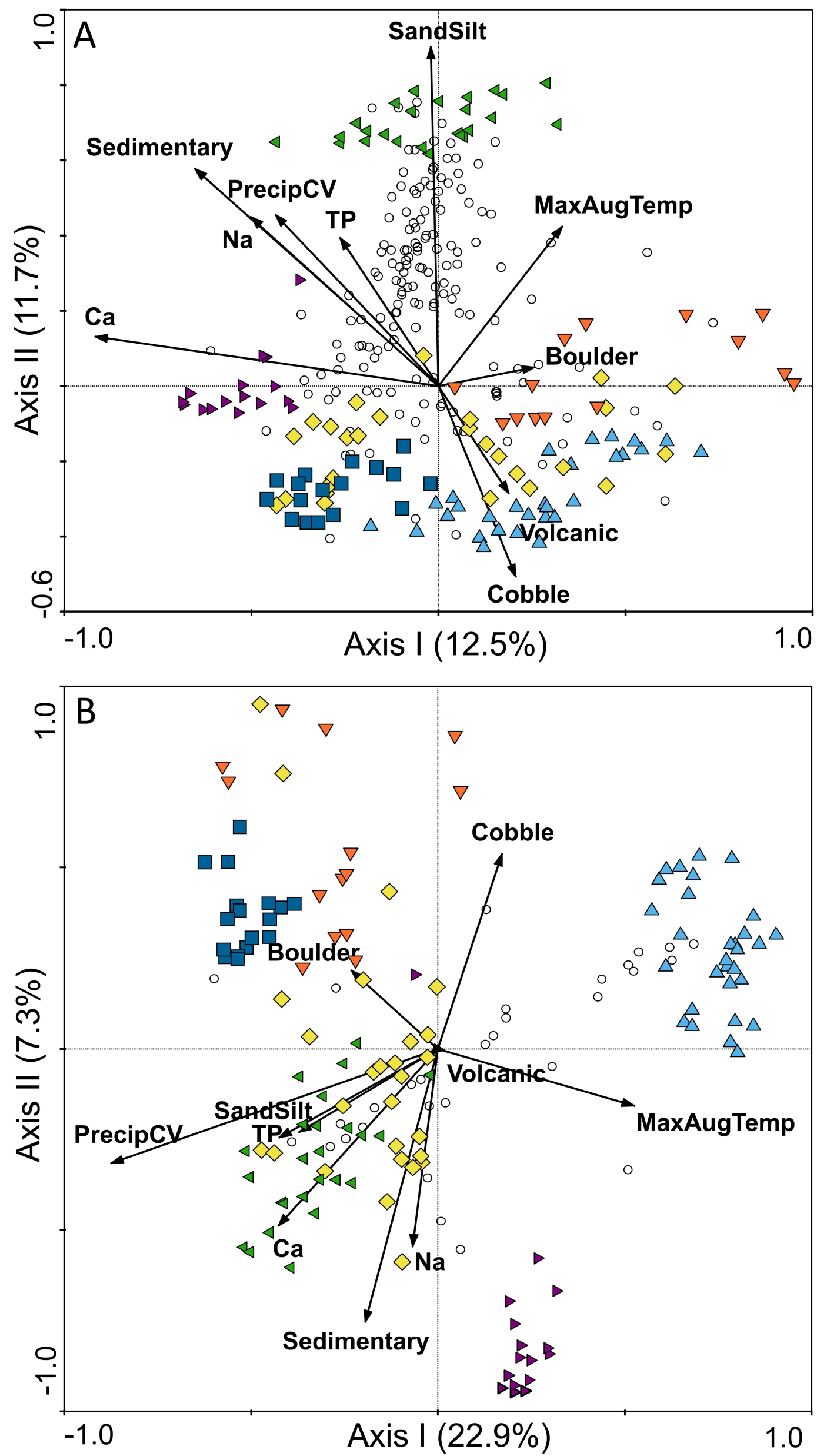

$\triangle 58 N$ East

$\nabla$ 63N East

$\diamond 72 N$ East

$\square$ 81N East

$72 \mathrm{~N}$ West

$\triangleleft$ Alaska (70N West) 
Data compiled
Nomenclature

(all FECs)
Site selection by

sampling method

(all FECs)

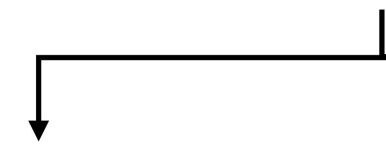

Convert all data to presence/absence

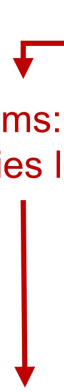

Group sites by hydrobasin/

ecoregion

$\downarrow$

Rarefy by

hydrobasin/

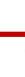

Fish: species

Combine across dates/replicates

Group sites by hydrobasin/

hydrobasin/ latitude by
hydrobasin/
ecoregion

ecoregion

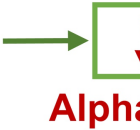

Alpha as a

function of latitude

Geospatial summarized by hydrobasin/ ecoregion

\section{Alpha as a function of geospatial variables}

$$
n=271
$$

level

$\downarrow$

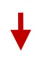

ecoregion

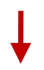

Rarefy by

ecoregion

Invertebrates: family level $\downarrow$

Combine across dates/replicates

Group sites by hydrobasin/ ecoregion

Rarefy by hydrobasin/ ecoregion

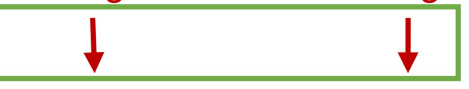

$\begin{array}{cc}\begin{array}{c}\text { Alpha as a } \\ \text { function of } \\ \text { latitude }\end{array} & \begin{array}{c}\text { Alpha as a } \\ \text { function of } \\ \text { latitude }\end{array}\end{array}$

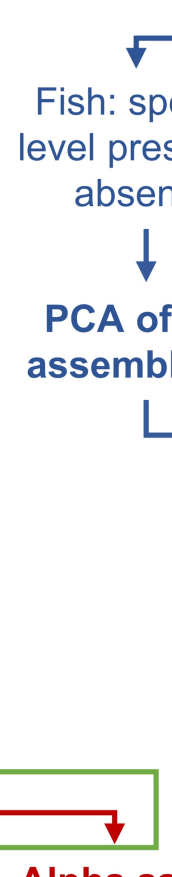

Alpha as a function of geospatial variables

$$
n=409
$$

\section{Alpha as a Alpha as a function of function of geospatial temperature and variables east/west region}

Match diatom and

Match fish and invertebrate sites

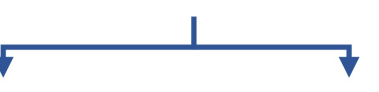
Analysis

$n=19$
Select multi-FEC sites 


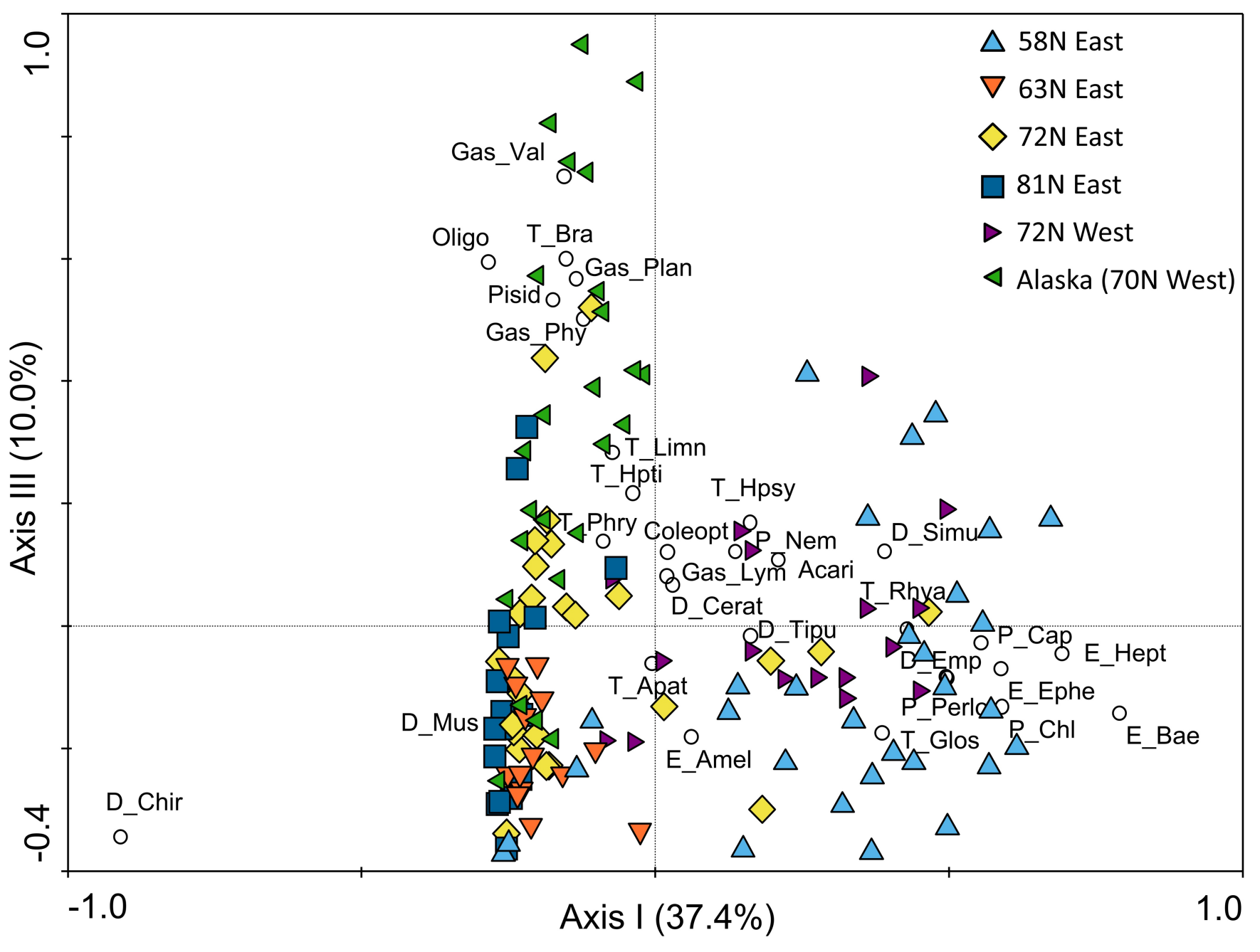

